\title{
Imaging spectrum of meningiomas: a review of uncommon imaging appearances and their histopathological and prognostic significance
}

\author{
Venkatram Krishnan ${ }^{A, B, C, D, E, F}$, Mahesh K. Mittal ${ }^{A, B, C, D, E}$, Mukul Sinha ${ }^{A, B, C, D}$, Brij B. Thukra ${ }^{A, B, C, D}$ \\ Vardhman Mahavir Medical College (VMMC) and Safdarjung Hospital, New Delhi, India
}

\begin{abstract}
Meningiomas are the most common primary non-glial intracranial neoplasms. In most cases, meningiomas have typical imaging appearances and locations, enabling a straightforward radiological diagnosis. However, a myriad of unusual appearances potentially complicate the imaging picture. Furthermore, certain imaging features can also predict the specific histopathological nature and WHO grade of the meningioma. 'Typical' meningiomas include meningothelial, fibrous, and transitional variants and have the characteristic imaging features described for meningiomas. Several 'atypical' variants exist, which, although less common, also generally have a less favourable prognosis and necessitate early diagnosis. In addition, meningiomas can occur in a variety of unusual intracranial and even extra-cranial locations and need to be distinguished from the more common tumours of these regions on imaging. Any associated oedema or haemorrhagic changes may alter the prognosis and have to be carefully assessed and reported. Cystic changes in meningiomas have been divided into five subtypes, and accurate characterisation is essential to predict the prognosis. An extensive review of the several possible variations in imaging appearances of meningiomas including the differential features of common and uncommon variants would facilitate informative radiological reporting of meningiomas. This would be expected to improve pre-operative planning prior to surgical biopsy and thereby improve disease prognosis and patient outcomes.
\end{abstract}

Key words: meningioma, typical meningioma, atypical meningioma, cystic meningioma.

\section{Introduction}

Meningiomas are the most common primary non-glial intracranial neoplasms, constituting about one-third of all central nervous system (CNS) tumours and about 16 to $20 \%$ of all intracranial neoplasms [1]. Meningiomas are easily detectable on imaging studies such as computed tomography (CT) and magnetic resonance imaging (MRI). They usually have characteristic imaging appearances and locations, enabling a straightforward radiological diagnosis. However, a myriad of unusual appearances potentially complicate the imaging picture and pose a diagnostic dilemma. Furthermore, subtle features on imaging give clues to predict the specific histopathological nature and World Health Organisation (WHO) grade of the meningioma. This radiological information would be expected to help surgeons improve surgical planning prior to biopsy and thereby improve patient management.

According to recent data from worldwide registries, the annual incidence of meningiomas lies between 1.28 and 7.8 per 100,000 [2]. The prevalence of meningiomas ranges between 50.4 and 70.7 per 100,000 [3]. It shows a significant female preponderance and is predominantly a tumour of old age. Although most meningiomas are histologically benign, the five-year survival rate of meningiomas is less than $70 \%$ and further declines with increasing patient age [4]. The long latent period and asymptomatic nature of slow-growing tumours are responsible for significant delays in diagnosis and management of meningiomas.

Intrinsic risk factors for meningioma include age, sex, ethnic group, family history, and genetic polymorphisms.

Correspondence address:

Prof. Mahesh Kumar Mittal, VMMC and Safdarjung Hospital, Ansari Nagar, near AllMS Hospital, New Delhi, Delhi 110029, India, e-mail: drmittalmk@gmail.com

Authors' contribution:

A Study design - B Data collection · C Statistical analysis · D Data interpretation - E Manuscript preparation · F Literature search · G Funds collection 
Turner's syndrome, Werner's syndrome, neurofibromatosis 2, and familial cancer syndromes involving NF1, PTCH, CREBBP, VHL, PTEN, and CDKN2A genes also predispose for the development of meningioma [5]. Several extrinsic risk factors such as electromagnetic fields, prior head injury, and nutritional, toxic, and hormonal factors have been identified as potential risk factors [6]. Meningiomas are usually asymptomatic. New onset headaches, seizures, focal neurological dysfunction, or cranial nerve palsies are the common presenting complaints in symptomatic cases and justify neuroimaging for diagnosis and further evaluation [7].

\section{WHO classification of meningiomas}

The 2016 WHO classification system is based on the pathological evaluation of meningioma tissues. It divides meningiomas into 15 subtypes, which are further categorised into three grades that predict the prognosis of the tumour [8]. Recurrence rate and mortality progressively increase, while successful gross total tumour resection rate and survival rate progressively reduce from WHO grade I to grade III tumours [9]. Subtle differences in imaging characteristics can predict specific histopathological subtypes, thereby enabling pre-operative prediction of the pathological meningioma subtype.

\section{Imaging features of meningioma variants}

Over $80 \%$ of meningiomas are of the meningothelial, fibrous, or transitional subtypes, with the meningothelial subtype comprising about $58 \%$ of cases [10]. These are the so-called 'typical' meningiomas. The remaining subtypes are the uncommon 'atypical' subtypes.

\section{WHO grade I}

\section{Meningothelial variant}

This is the most common variant of meningioma, consisting histologically of meningothelial cells, and showing the classical imaging findings described for meningioma. It appears hyperdense on non-enhanced CT (NECT), isointense to hypointense on T1WI, isointense to hyperintense on T2WI, and shows intense homogeneous post-contrast enhancement on both contrast-enhanced CT (CECT) and T1WI contrast-enhanced (T1WI-CE) MRI sequence (Figure 1). It usually shows no diffusion restriction. Hyperostosis of the underlying bone, CSF cleft around the tumour, and an enhancing dural tail are other classical features [11]. Inward buckling of the cortical grey matter is also seen, indicating its extra-axial nature. Intratumoural calcifications may be present. On MR spectroscopy (MRS), alanine peak and glutamine/glutamate peak are seen. Alanine peak is relatively specific for meningiomas [12]. Appearance of the tumour on T2WI is important in differentiating between the three subtypes of 'typical' meningiomas.

\section{Fibrous variant}

This is the second subtype of 'typical' meningioma. The appearance is similar to that of meningothelial meningioma; however, it shows prominent hypointensity on T2WI due to the presence of a fibrous component. Furthermore, the enhancement pattern, although homogeneous, is less intense and relatively delayed as compared to the meningothelial variant (Figure 2).

\section{Transitional variant}

The final subtype of 'typical' meningiomas, the transitional variant, contains both meningothelial and fibrous components and has a heterogeneous appearance on T2WI and heterogeneous post-contrast enhancement (Figure 3).

\section{Psammomatous variant}

This variant is characterised by the presence of psammoma bodies on histology. On imaging, the characteristic feature of this variant is the prominent dense intratumoural calcification, present either diffusely or in the periphery of the meningioma. Spinal meningiomas, particularly those in the thoracic spine, show a propensity to psammomatous histology [13]. The calcification is easily visualised as prominent hyperdense areas on NECT and as prominent areas of signal loss (blooming) on gradient echo (GRE) or susceptibility weighted (SWI) sequences (Figure 4). Strong post-contrast enhancement is seen in the non-calcified parts of the tumour.

\section{Angiomatous variant}

This is a rare subtype of meningioma with a male preponderance characterised by a predominance of large blood vessels on histology. Prominent internal and peritumoral flow voids are visible on MRI. An extra-axial space-occupying lesion with large and prominent feeding vessels are appreciable on post-contrast scans. CT angiography (CTA) and MR angiography (MRA) can depict the extensive network of enlarged intratumoural and peritumoural feeding vessels of the tumour (Figure 5). Vivid post-contrast enhancement and disproportionately large peritumoral oedema are other characteristic features of this subtype [14]. Despite the aggressive appearance of this variant, the prognosis is relatively good.

\section{Microcystic variant}

This is the rarest histological subtype of meningioma and is characterised by intratumoural microcystic spaces on histology. It has a characteristic hypodense or isodense 

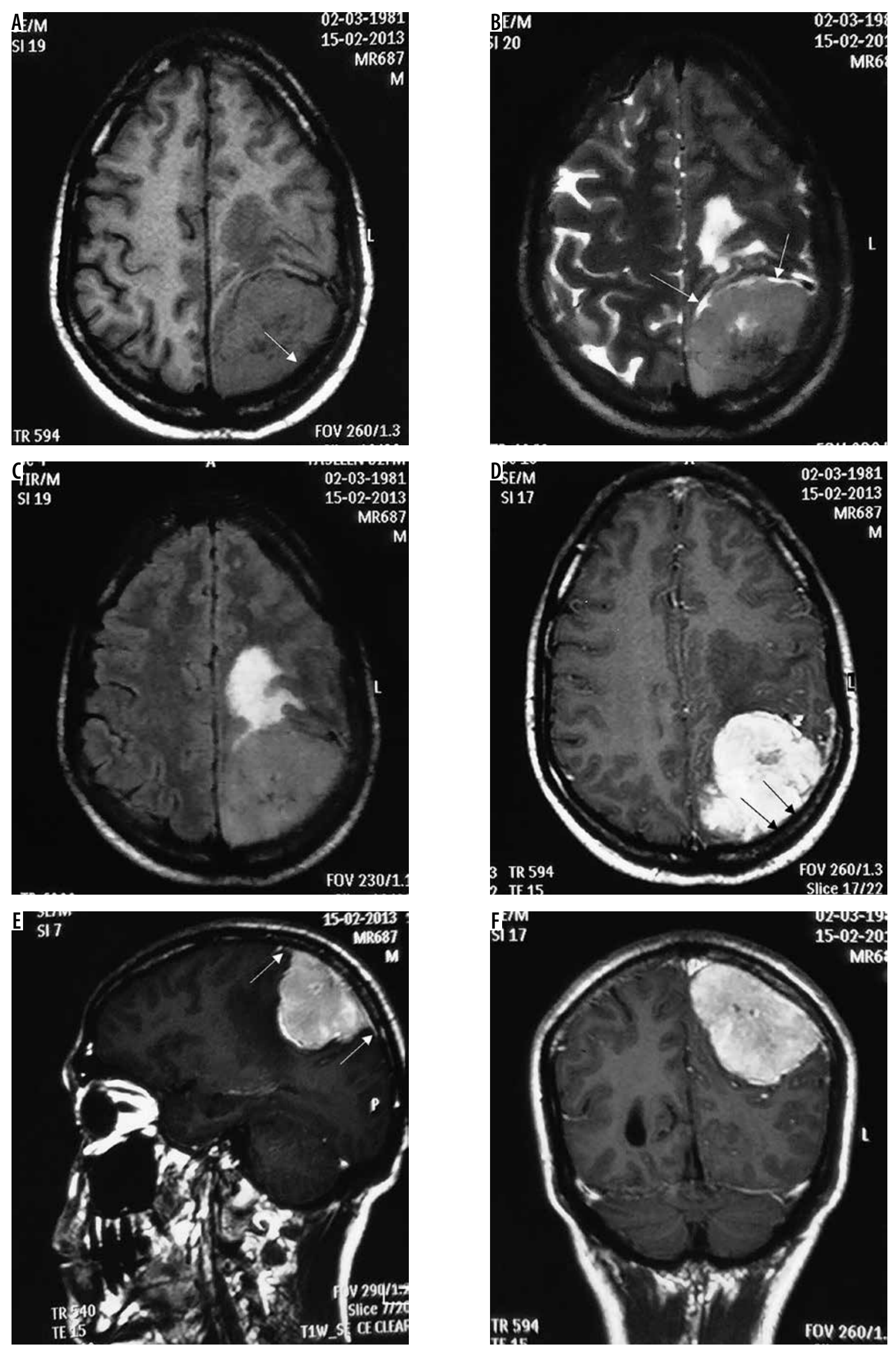

Figure 1. Typical parietal convexity meningothelial meningioma (arrow in $A$ ). The mass appears mildly hypointense on T1W (A), mildly hyperintense on T2W (B) and FLAIR (C), and shows intense homogeneous enhancement T1W-CE (D, E, and F). Characteristic CSF cleft (arrows in B), dural tail (arrows in E), and hyperostosis (arrows in D) are visible. Underlying brain parenchyma shows moderate oedema 

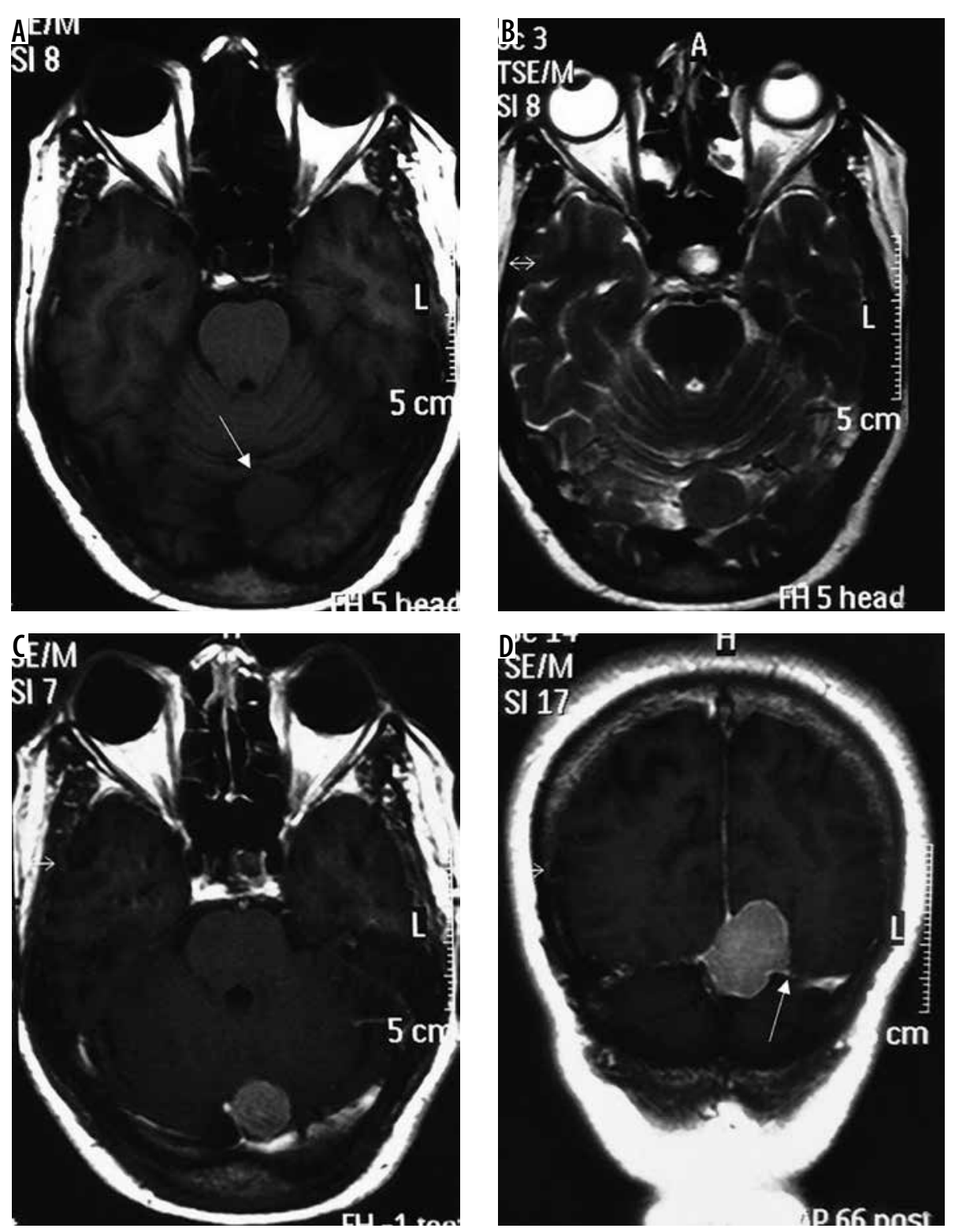

Figure 2. Fibrous variant of meningioma in tentorium (arrows in A and D). The lesion is isointense to mildly hypointense on T1W (A), hypointense on T2W (B), and shows homogeneous enhancement on T1W-CE (C and D), which is less intense than in the meningothelial variant

appearance on NECT, in contrast to the hyperdense appearance of other meningiomas. On MRI, distinctive prominent hypointensity on T1W has been identified as the only significant predictor of microcystic subtype [15]. Post-contrast reticular enhancement is also characteristic of this subtype (Figure 6), although it is only seen in $30 \%$ of cases.

\section{Secretory variant}

Pseudo-psammoma bodies (intracellular eosinophilic inclusions) characterise this subtype of meningioma on histology. It shows a predilection for skull base location. The distinguishing feature of the secretory variant on imaging is the characteristic intense hyperintensity on $\mathrm{T} 2 \mathrm{~W}$, which is seen in up to $96 \%$ of cases [16]. In many cases, the intensity of the tumour on T2W nearly parallels that of CSF (Figure 7).

\section{Lymphoplasmacyte-rich variant}

This is a rare subtype presenting in relatively young patients with secondary hypergammaglobulinaemia and anaemia. Chronic inflammatory infiltrates characterise the histological picture. On imaging it forms a characteristic en-plaque pattern with irregular margins extending along the dura, which appears isodense to hyperdense on NECT and isointense to hypointense on T1WI. It has variable signal intensity on T2WI. Post-contrast scan shows intense homogeneous enhancement (Figure 8). Another characteristic feature is the presence of diffusion restriction, in contrast to other WHO grade I meningiomas. 

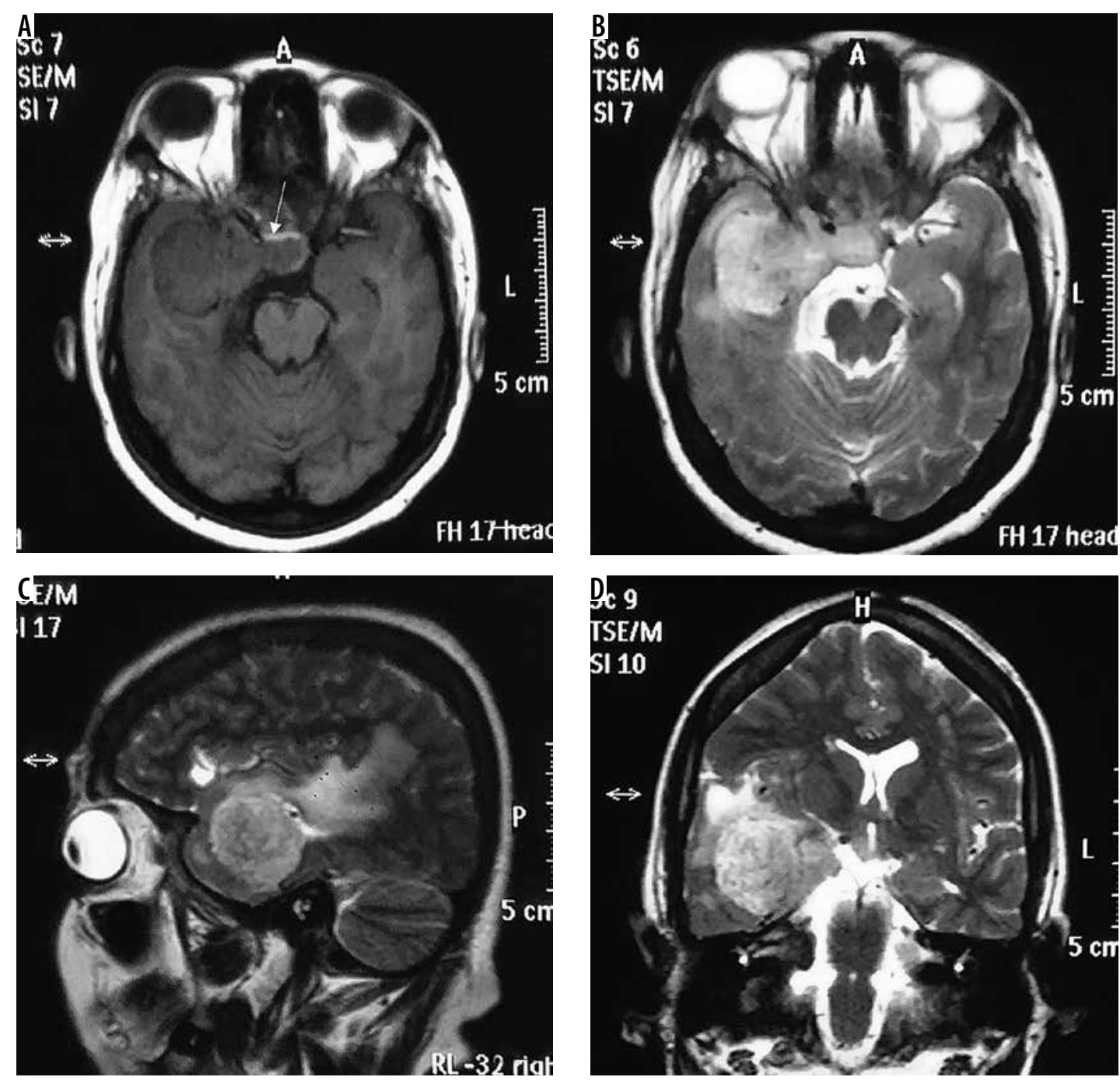

Figure 3. Transitional variant of meningioma in sellar and parasellar location (arrow in $A$ ). The lesion is mildly hypointense on T1W (A) with heterogeneous appearance on T2W (B, C, and D) due to the presence of both meningothelial and fibrous components

Underlying brain parenchyma commonly shows oedema and cystic changes [17]. Although the appearance is characteristic in relation to other types of meningiomas, the en-plaque lesion itself potentially has a large spectrum of differentials such as hypertrophic pachymeningitis, histiocytic disorders, tubercular pachymeningitis, connective tissue disorders, neurosarcoidosis, and lymphoma, from which it may sometimes be indistinguishable on the basis of imaging alone.

\section{Metaplastic variants}

Histologically, this variant is characterised by the presence of focal or diffuse mesenchymal components, which may be osseous, chondroid, myxoid, lipomatous, or xanthomatous in nature. Imaging features are variable and depend on the mesenchymal component present. Usually specific features of mesenchymal components are superimposed on a background of tumour tissue, with typical imaging characteristics of a meningioma. For instance, xanthomatous meningioma shows diffuse hypodensity on NECT with focal areas of fat attenuation and small fat components on MRI (Figure 9). Lipomatous variant, a close differential on imaging, shows larger areas of intratumoural fat [18].

\section{WHO Grade II}

\section{Chordoid variant}

This variant shows histological similarity to chordomas with presence of mucoid matrix, which gives specific diffusion characteristics to the tumour. It is associated with Castleman disease in childhood, although this is rare. Its characteristic imaging feature is the presence of high diffusivity with facilitated diffusion, appearing hyperintense on apparent diffusion coefficient (ADC) maps and hypointense on diffusion-weighted (DWI) sequence (Figure 10). It has the highest mean $\mathrm{ADC}$ value of all meningiomas $\left(1.62 \pm 0.33 \times 10^{-3} \mathrm{~mm}^{2} / \mathrm{s}\right)$, the values being almost double that of grade I $\left(0.88 \pm 0.13 \times 10^{-3} \mathrm{~mm}^{2} / \mathrm{s}\right)$ and non-chordoid grade II $\left(0.84 \pm 0.11 \times 10^{-3} \mathrm{~mm}^{2} / \mathrm{s}\right)$ menin- 

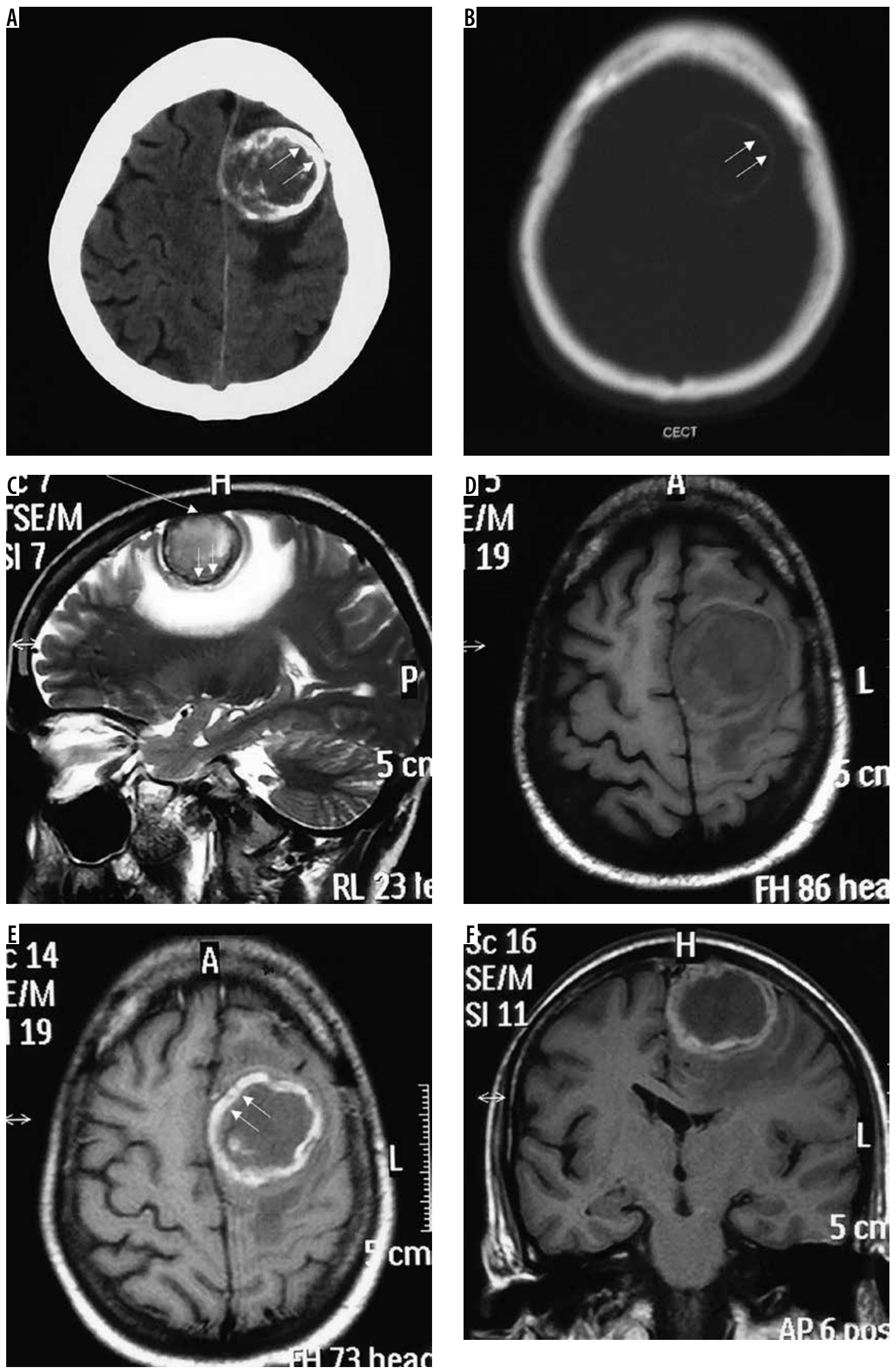

Figure 4. Psammomatous variant of meningioma in frontoparietal convexity location (long arrow in C). Dense calcifications are evident in the periphery of the lesion on NECT (arrows in A) and are also appreciable on bone window (arrows in B), which appear as areas of signal loss on T2W (short arrows in C). The lesion appears mildly hypointense on T1W (D) and shows peripheral enhancement on T1W-CE (arrows in E and F) 

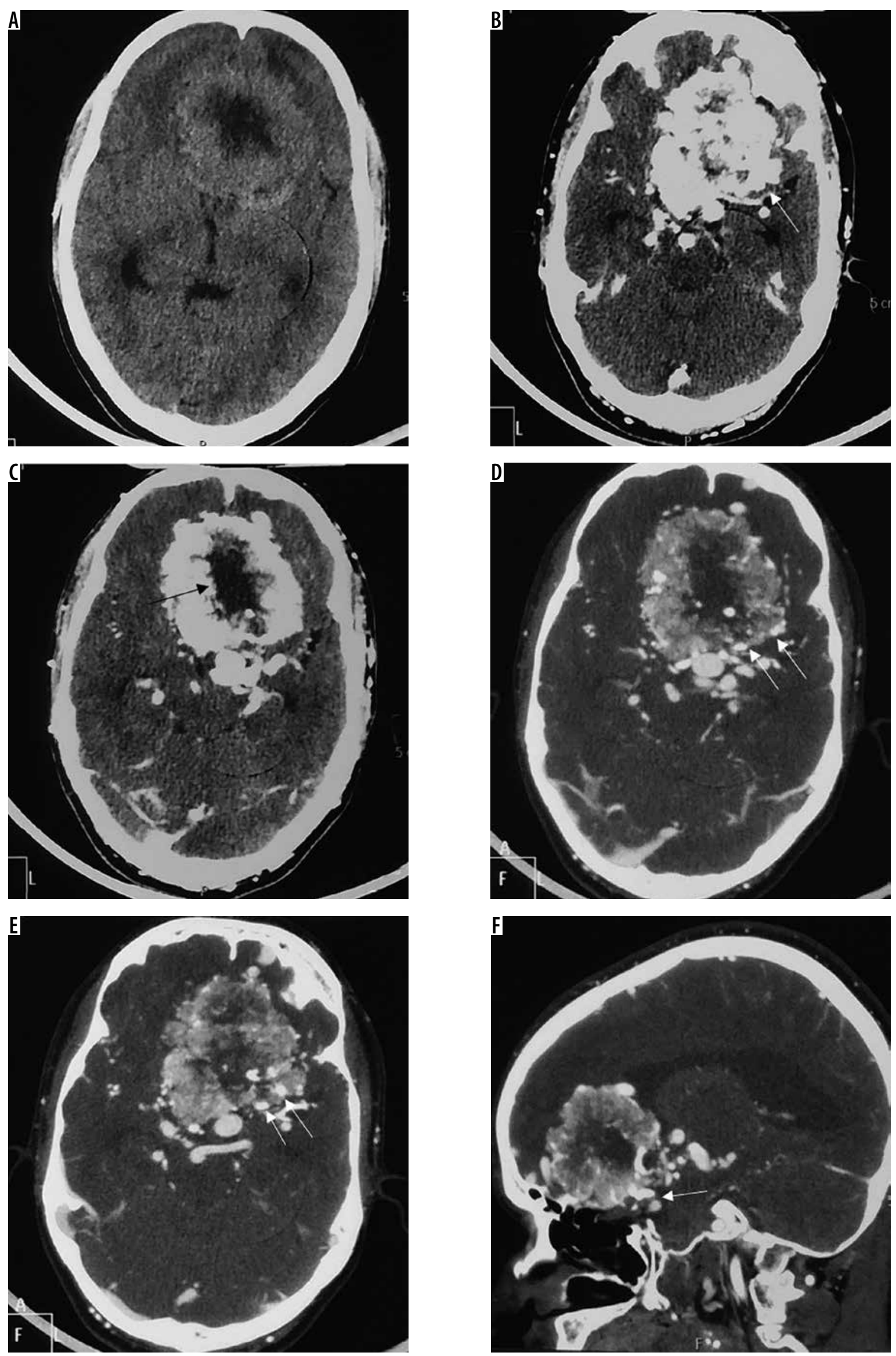

Figure 5. Angiomatous variant of meningioma in anterior skull base location (arrow in F). The mass appears mildly hyperdense on NECT (A) and shows intense post-contrast enhancement (arrow in B) with prominent intratumoural and peritumoral feeding vessels evident in the arterial phase on computed tomography angiography (arrows in D and E). It also shows type I cystic change (arrow in C) 

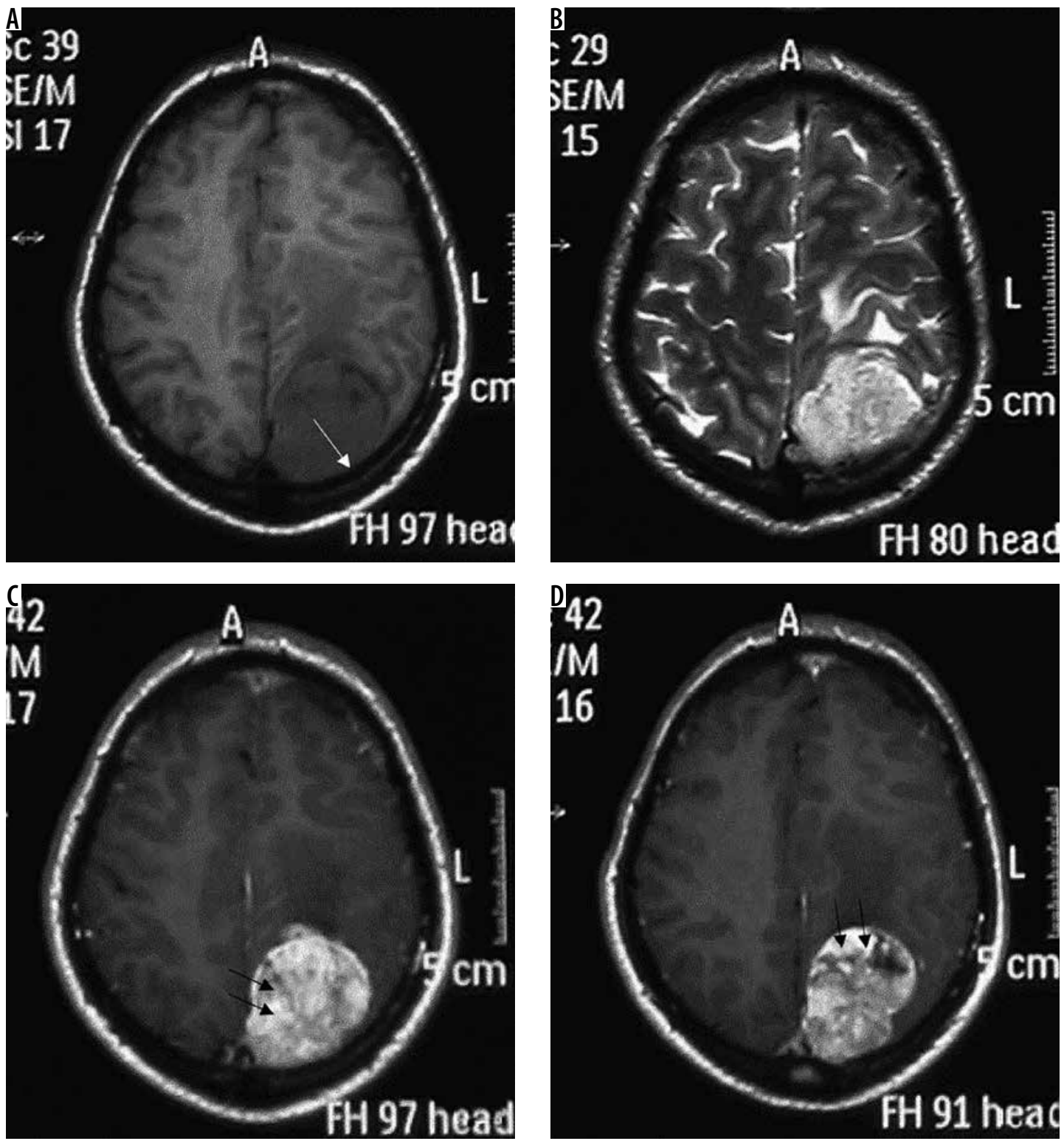

Figure 6. Microcystic variant of meningioma in posterior parietal convexity location (arrow in A). The lesion shows characteristic T1W hypointensity (A) and T2W mild hyperintensity (B) with a characteristic reticular pattern of enhancement on T1W-CE (arrows in C and D)

giomas; grade III meningiomas show diffusion restriction with low mean ADC values $\left(0.57 \times 10^{-3} \mathrm{~mm}^{2} / \mathrm{s}\right)[19]$.

\section{Clear cell variant}

This subtype is histologically comprised of polygonal cells with clear cytoplasm. It shows a predilection for younger patients and cerebellopontine (CP) angle location (Figure 11). Usually these tumours show a heterogeneous enhancement pattern. Peritumoral oedema and cyst formation in the underlying brain parenchyma is common. Being a WHO grade II tumour, osteolysis of the underlying bones is more common than hyperostosis [20], and hence this feature cannot be used to differentiate $\mathrm{CP}$ angle clear cell meningioma from the more common $\mathrm{CP}$ angle tumour, acoustic schwannoma. However, certain imaging clues do exist, which can be used to differentiate them (Table 1) [21].

\section{Atypical variant and WHO grade III meningiomas}

Atypical subtype of grade II and all three subtypes of grade III meningiomas can essentially be differentiated only based on histopathology and cannot be definitively differentiated from each other on imaging. However, on the basis of imaging findings, a prediction of high-grade meningioma can be made by the radiologist [22]. They occur in relatively old patients and show a male predominance. Imaging features predicting a high-grade meningioma include an extra-axial mass showing irregular tumour margins with indistinct tumour-brain interfaces, lack of sharply defined enhancement margins, heterogeneous signal intensity and enhancement pattern, eccentric intratumoural necrosis, extensive peritumoral oedema, definite invasion of underlying brain parenchyma, and destruction of the overlying bone (Figure 12). 

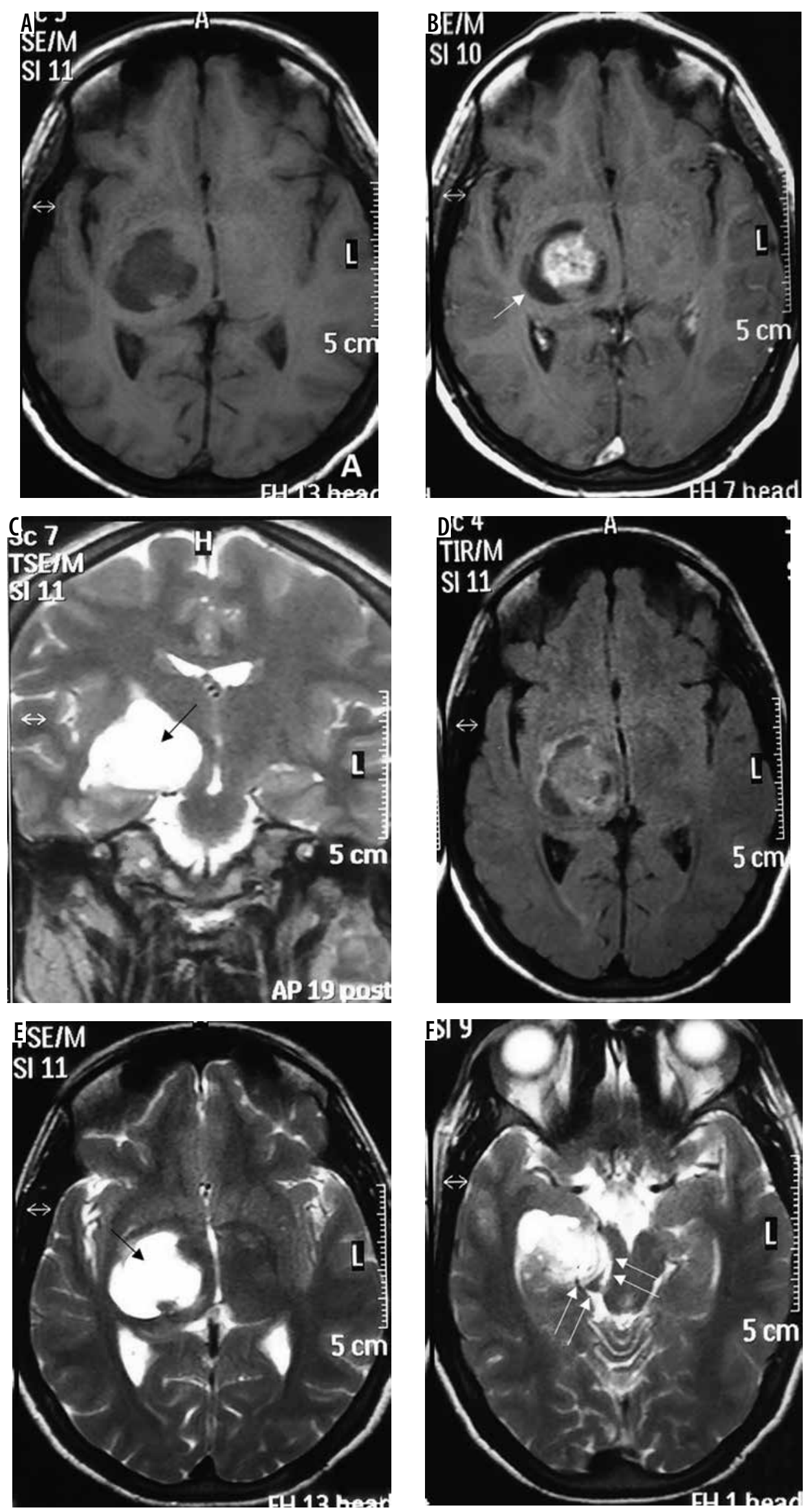

Figure 7. Secretory variant of meningioma in the basal cistern (arrows in F). The lesion appears hypointense on T1W (A) and characteristically intensely hyperintense on T2W (arrows in ( and E). The lesion can be differentiated from the perilesional cystic change only on FLAIR (D). It shows moderately intense enhancement on T1W-CE (B). It also shows type III cystic change (arrow in B) 

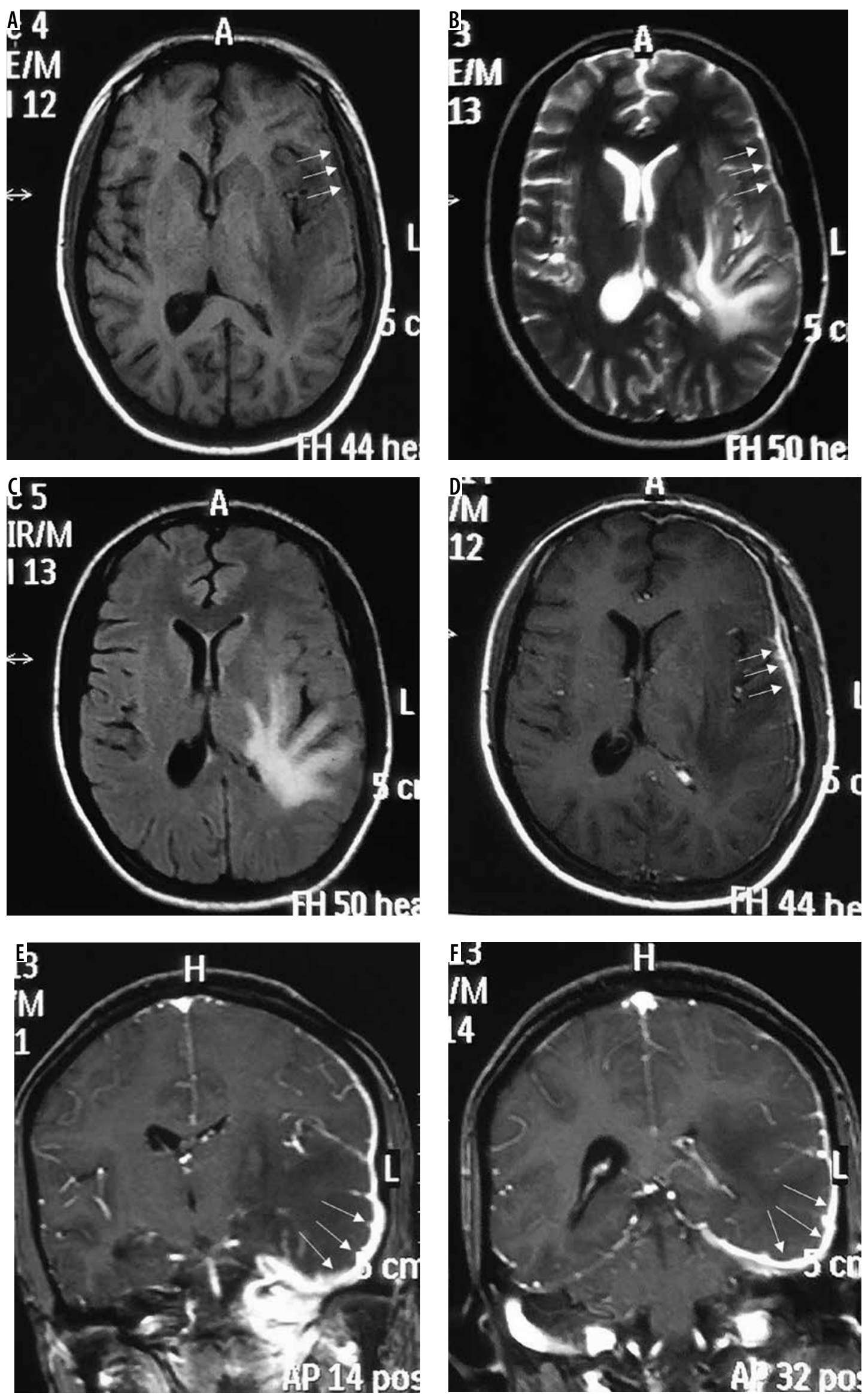

Figure 8. Lymphoplasmacyte-rich variant of meningioma (en-plaque type). Subtle thickening of the dura is seen along the left frontoparietotemporal convexity, which appears isointense on T1W (arrows in A) and hypointense on T2W (arrows in B) and FLAIR (C). It shows intense enhancement on T1W-CE (arrows in D, E, and F) on which it is easily appreciated. Underlying brain parenchyma shows prominent oedema 

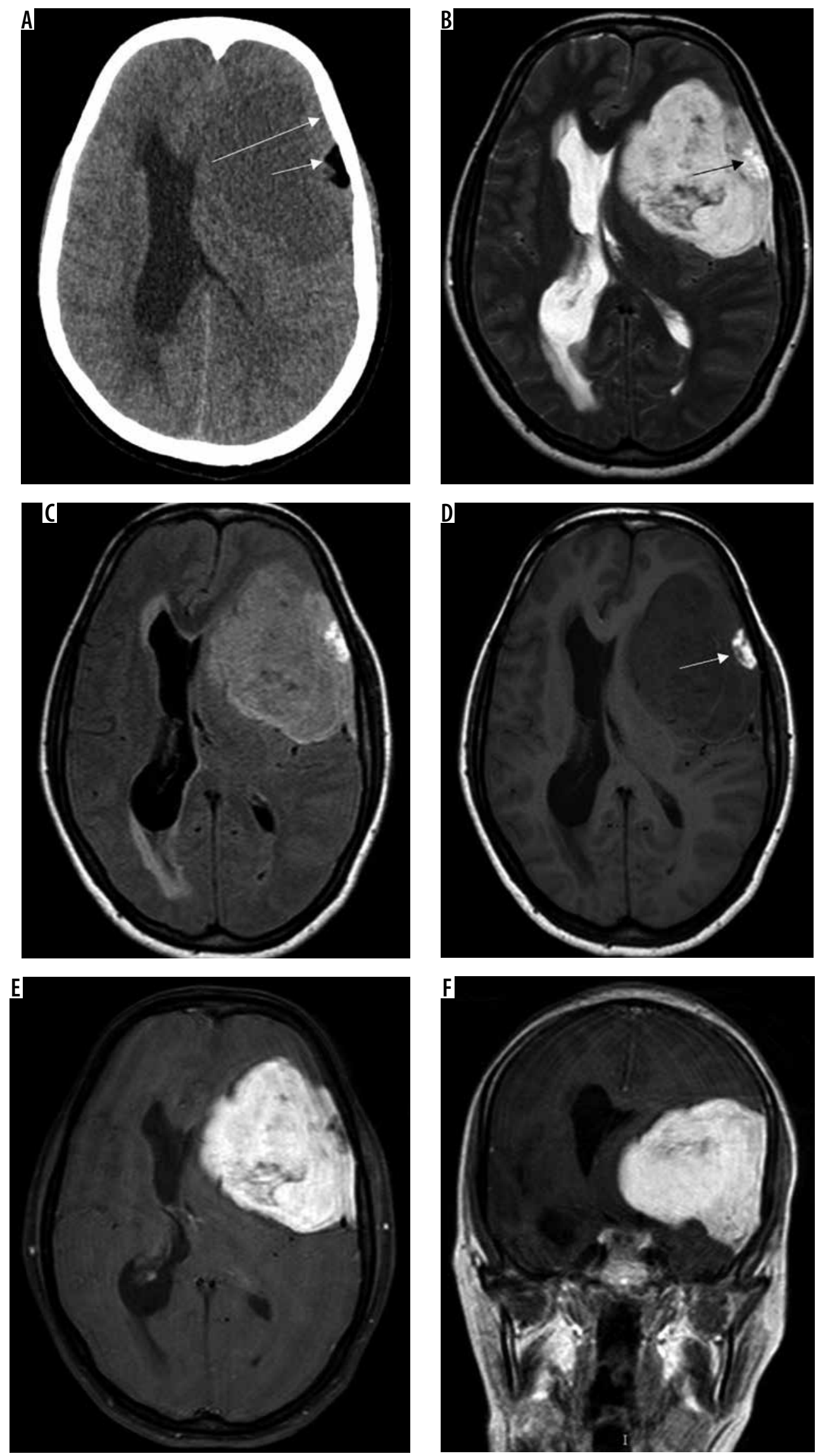

Figure 9. Metaplastic (xanthomatous variant) meningioma along left frontoparietal convexity (long arrow in A). The mass characteristically appears mildly hypodense on NECT (A). Other features are those of typical meningiomas, appearing hyperintense on T2W (B) and FLAIR (C) and mildly hypointense on T1W (D) with intense enhancement on T1W-CE (E and F). However, a focal area of fat attenuation is appreciable on NECT (arrow in A), which appears hyperintense on T1W (arrow in D) and T2W (arrow in B), indicating fat intensity 

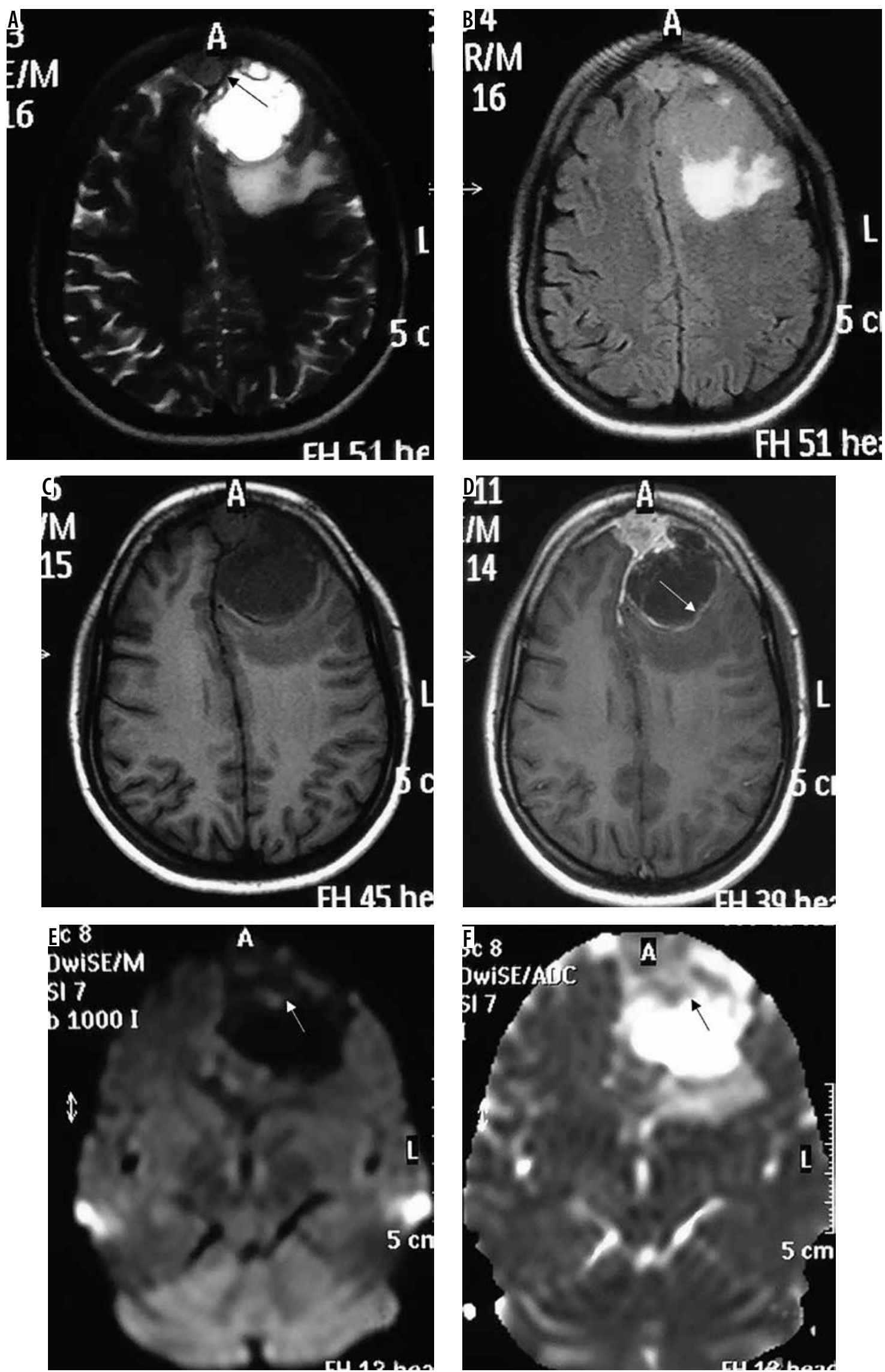

Figure 10. Chordoid meningioma of anterior falx (arrow in A). Signal characteristics of the lesion are similar to typical meningiomas, being mildly hypointense on T1W (C) and isointense on T2W (A) and FLAIR (B) with intense enhancement on T1W-CE (D). The lesion is characteristically hypointense on DWI (arrow in $\mathrm{E}$ ) and hyperintense on ADC map (arrow in F), suggesting facilitated diffusion. It also shows Type $V$ cystic change with enhancement of the cyst wall (arrow in D), implying the presence of tumour cells in the wall, an indicator of its aggressive nature (grade II) 

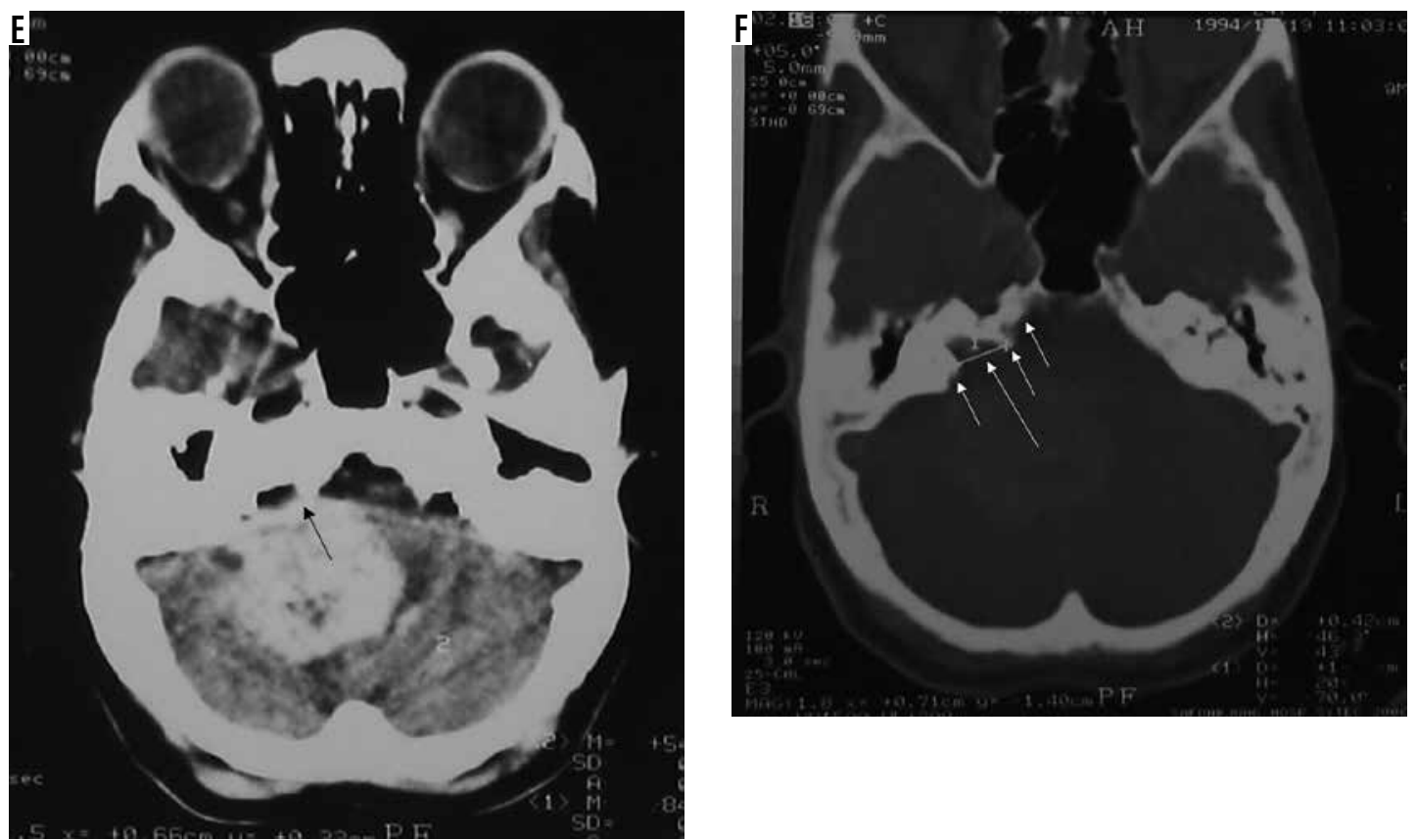

Figure 11. Clear cell variant of meningioma in the right cerebellopontine angle (arrow in A). The mass shows intense enhancement on CECT (A) with apparent widening of the right internal auditory meatus on bone window (long arrow in B) due to characteristic osteolysis, which also extends medially to the petrous apex (short arrows in B). Osteolysis indicates its aggressive nature (grade II)

Table 1. Imaging differences between cerebellopontine (CP) angle meningioma and acoustic schwannoma

\begin{tabular}{|l|l|}
\hline Meningioma & Acoustic schwannoma \\
\hline $\begin{array}{l}\text { Sessile, broad based towards } \\
\text { petrous base }\end{array}$ & Globular \\
\hline $\begin{array}{l}\text { Usually cause no widening of CP } \\
\text { angle }\end{array}$ & $\begin{array}{l}\text { Usually cause widening of CP } \\
\text { angle }\end{array}$ \\
\hline $\begin{array}{l}\text { Intratumoural calcification more } \\
\text { common }\end{array}$ & $\begin{array}{l}\text { Intratumoural calcification less } \\
\text { common }\end{array}$ \\
\hline Presence of dural tail & Absence of dural tail \\
\hline $\begin{array}{l}\text { Usually show intense } \\
\text { enhancement }\end{array}$ & $\begin{array}{l}\text { Usually show moderate } \\
\text { enhancement }\end{array}$ \\
\hline
\end{tabular}

In contrast to grade I and other grade II meningiomas, these show diffusion restriction [23]. On dynamic contrast-enhanced MRI, the volume transfer constant $\mathrm{K}^{\text {trans }}$ shows higher values as compared to other meningiomas. MRS may be necessary for confirmation if conventional imaging findings are not sufficiently diagnostic of meningioma and it shows an alanine peak (specific) and glutamine/glutamate peak in the tumour. Important differentials of high-grade meningiomas include haemangiopericytoma (differentiated from meningioma by the presence of myoinositol peak on MRS) and metastases (usually differentiated from meningioma by the presence of multiple lesions).

The main differentiating features on imaging of the various histopathological subtypes of meningiomas are shown in Table 2.
Table 2. Distinguishing features of subtypes of meningioma

\begin{tabular}{|l|l|}
\hline Pathological subtype & Distinguishing imaging features \\
\hline Meningothelial & Classical meningioma pattern \\
\hline Fibrous & T2W hypointensity \\
\hline Transitional & T2W heterogeneous appearance \\
\hline Psammomatous & Dense calcification \\
\hline Angiomatous & $\begin{array}{l}\text { Large, prominent intratumoural and } \\
\text { peritumoral feeding vessels }\end{array}$ \\
\hline Microcystic & T1W hypointensity \\
\hline Secretory & Skull base location, T2W hyperintensity \\
\hline Lymphoplasmacyte-rich & En-plaque pattern \\
\hline Metaplastic & $\begin{array}{l}\text { Mesenchymal components on background } \\
\text { of meningioma }\end{array}$ \\
\hline Chordoid & High mean ADC values \\
\hline Clear cell & Cerebellopontine angle location, osteolysis \\
\hline $\begin{array}{l}\text { Atypical and WHO } \\
\text { grade III }\end{array}$ & $\begin{array}{l}\text { III-defined margins, diffusion restriction, } \\
\text { high Ktrans }\end{array}$ \\
\hline
\end{tabular}

\section{Uncommon locations of meningioma}

Common locations of meningiomas include parasagittal region (Figure 13), cerebral convexity (Figure 1), and sphenoid wing (Figure 12), which account for about $70 \%$ of meningiomas. Meningiomas can also occur in several uncommon intracranial and extracranial locations and need to be distinguished from the more common tumours of these regions on imaging [11]: 

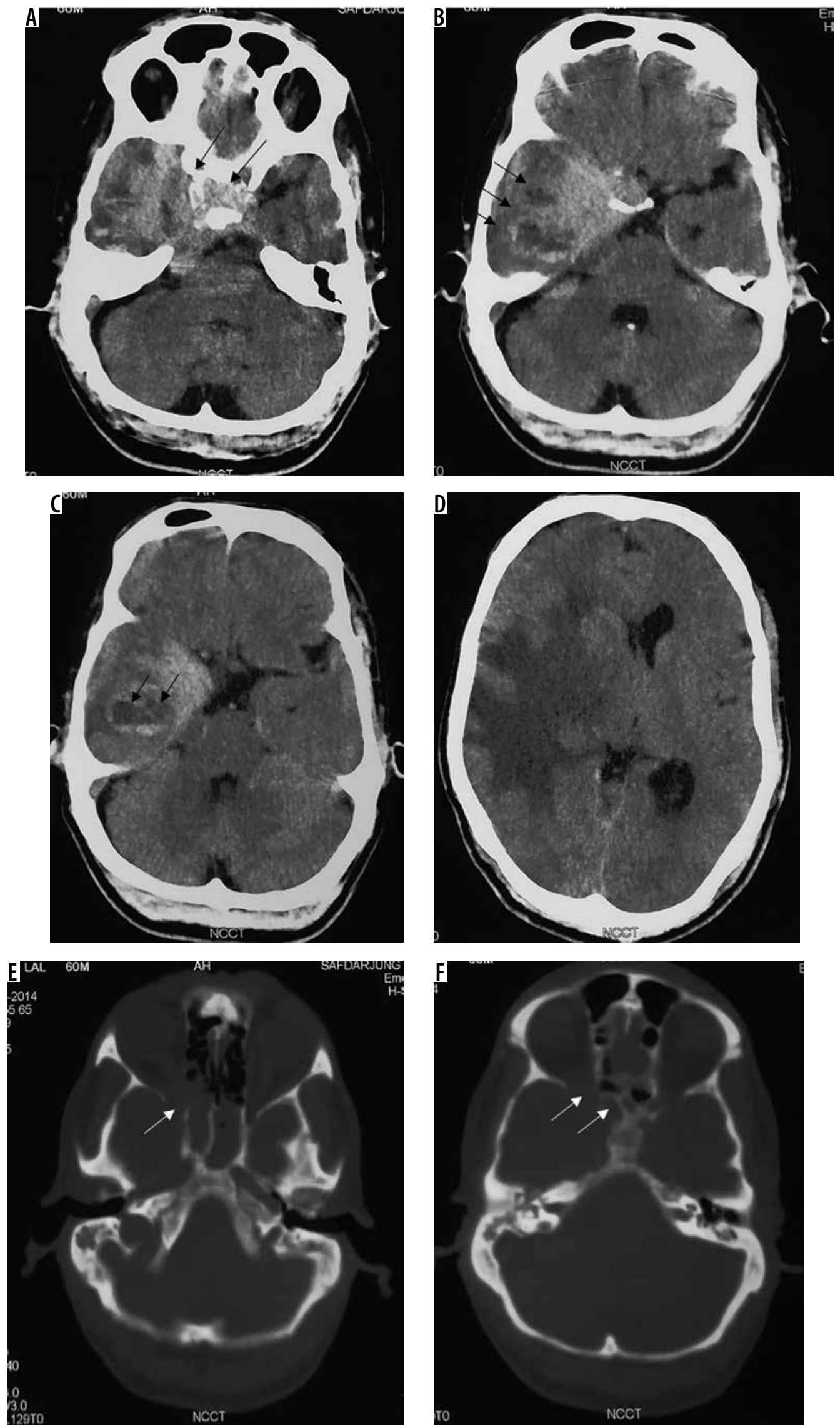

Figure 12. Atypical/high-grade (grade III) meningioma in the sellar and parasellar region extending to the sphenoid wing (arrows in A). The mass shows heterogeneous enhancement with irregular margins and indistinct tumour-brain interfaces (arrows in B), intratumoural necrotic areas (arrows in C), extensive perilesional brain oedema (D), and destructive changes in the sphenoid bone (arrows in E and F), all indicators of its aggressive nature. It also shows type Il cystic change (arrows in C) 

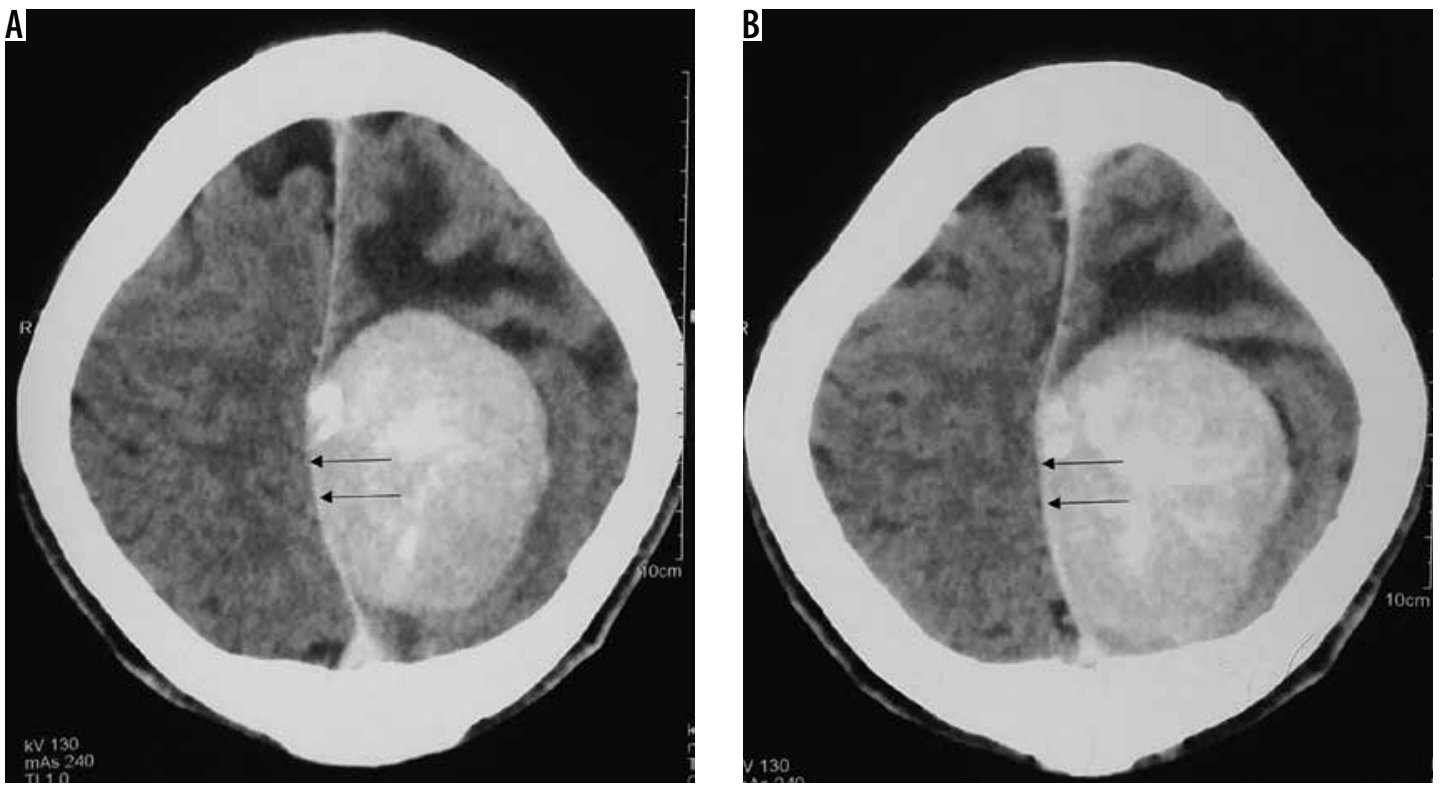

Figure 13. Parasagittal meningioma arising from the falx (arrows in A and B)
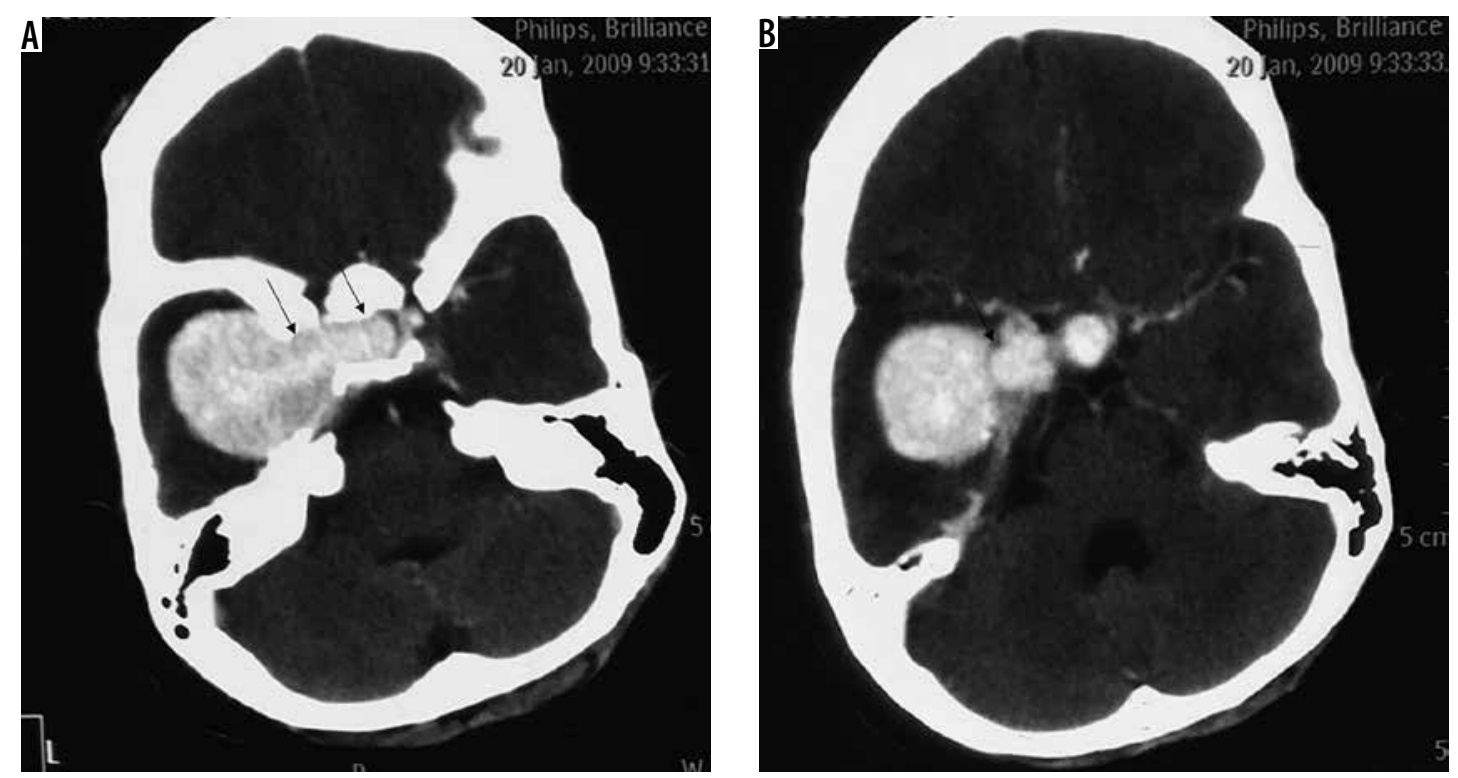

Figure 14. Sellar meningioma with suprasellar and parasellar extension (arrows in A and B)

- skull base: usually secretory variant (Figure 7); differentials include other skull base mass lesions depending on location, such as chondrosarcoma, chordoma, multiple myeloma, histiocytic disorders, or metastases;

- cerebellopontine angle: Usually clear cell variant (Figure 11); differentials include other CP angle masses, especially acoustic schwannoma;

- sellar/suprasellar/parasellar meningiomas (Figure 14): Differentials include craniopharyngioma or pituitary tumours;

- posterior fossa meningiomas (Figure 15): Differentials include other posterior fossa extra-axial masses such as paragangliomas (particularly the hyperostotic variant) and schwannomas;
- tentorial/tentorial apex meningiomas (Figure 16);

- intraventricular/choroid plexus meningiomas (Figure 17): differentials include more common intraventricular lesions such as choroid plexus papilloma (differentiated by its lobulated appearance and presence of hydrocephalus), subependymoma (differentiated by its weak post-contrast enhancement);

- optic nerve sheath meningioma (Figure 18): differential includes optic nerve glioma, usually differentiated by the visualisation of the optic nerve coursing through the meningioma ('tram track sign');

- orbital wall meningioma (Figure 19): differentials include other extraconal orbital lesions; 

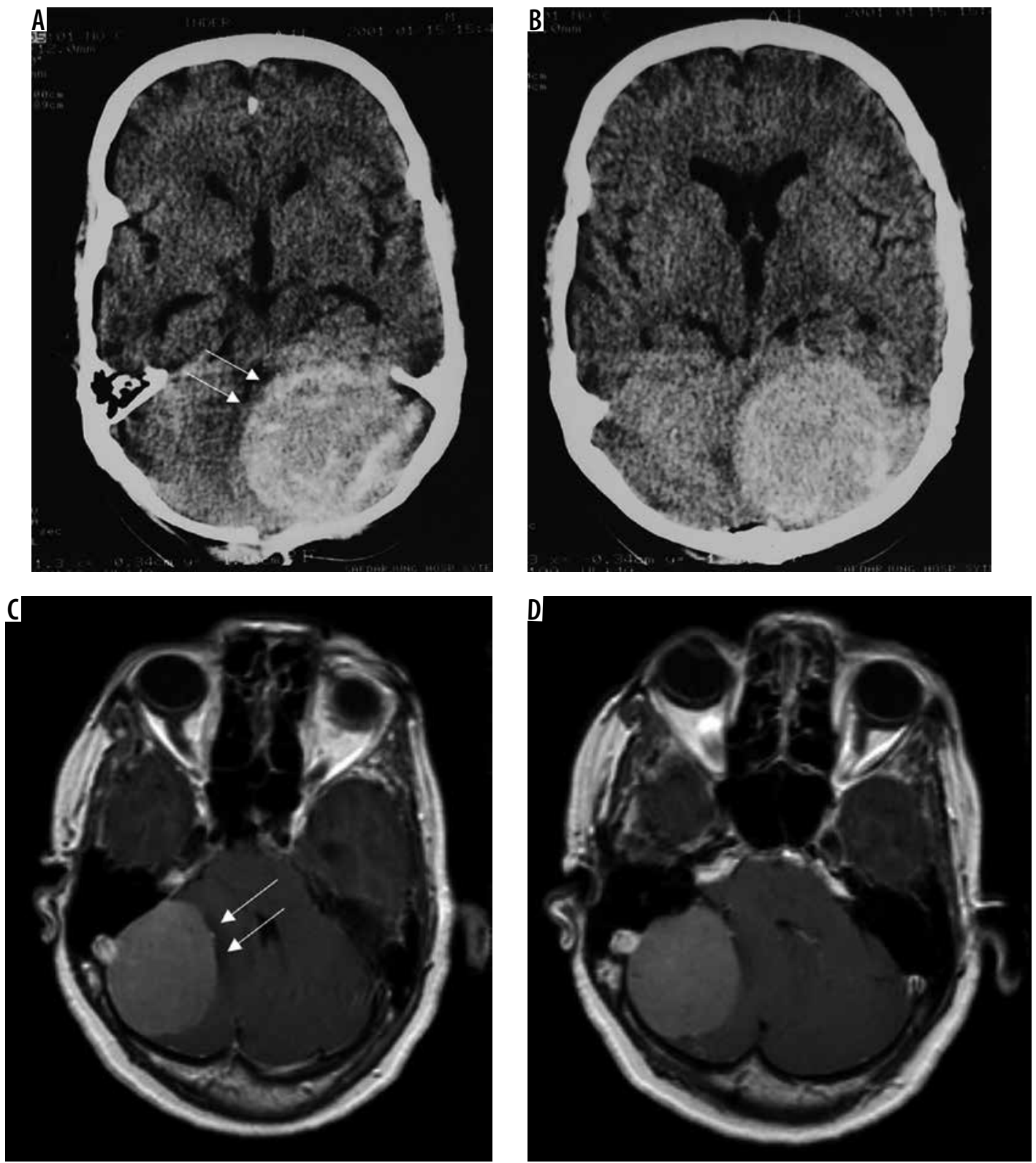

Figure 15. Two cases of posterior fossa meningiomas, one on the left side (arrows in A and B) and the other on the right side (arrows in C and D)

- spinal canal meningioma: thoracic spinal canal meningioma is usually of the psammomatous variant (Figures 20 and 21) - differentials include other extramedullary spinal canal lesions;

- ectopic meningiomas: These are extremely rare and may involve the head and neck, mediastinum, retroperitoneum, pelvis, or extremities. They probably arise from meningothelial cell rests in these regions. Differentials are extensive, and diagnosis is usually made only on histopathology.

\section{Oedematous brain changes in meningioma}

Oedema has been reported to be associated with meningiomas in as many as $60 \%$ of cases [24] and is usually vasogenic in nature. Oedema is most frequently associated with microcystic, angiomatous, and lymphoplas- macyte-rich variants. It is least common in the posterior fossa location of meningiomas. There are some imaging findings that predict occurrence of oedema [25]:

- pial blood vessels supplying the tumour,

- absence of CSF cleft between tumour and brain,

- irregular tumour margins,

- T2W hyperintensity (higher water content).

\section{Haemorrhagic changes in meningioma}

Haemorrhage in meningioma is uncommon. It is more common in the fibrous variant of meningioma. Intraventricular and convexity location of meningiomas show a higher propensity to haemorrhage. It has no association with the angiomatous subtype or the grade of meningioma [26]. Diagnosis is usually straightforward on NECT or GRE/SWI sequences on MRI (Figure 22). 

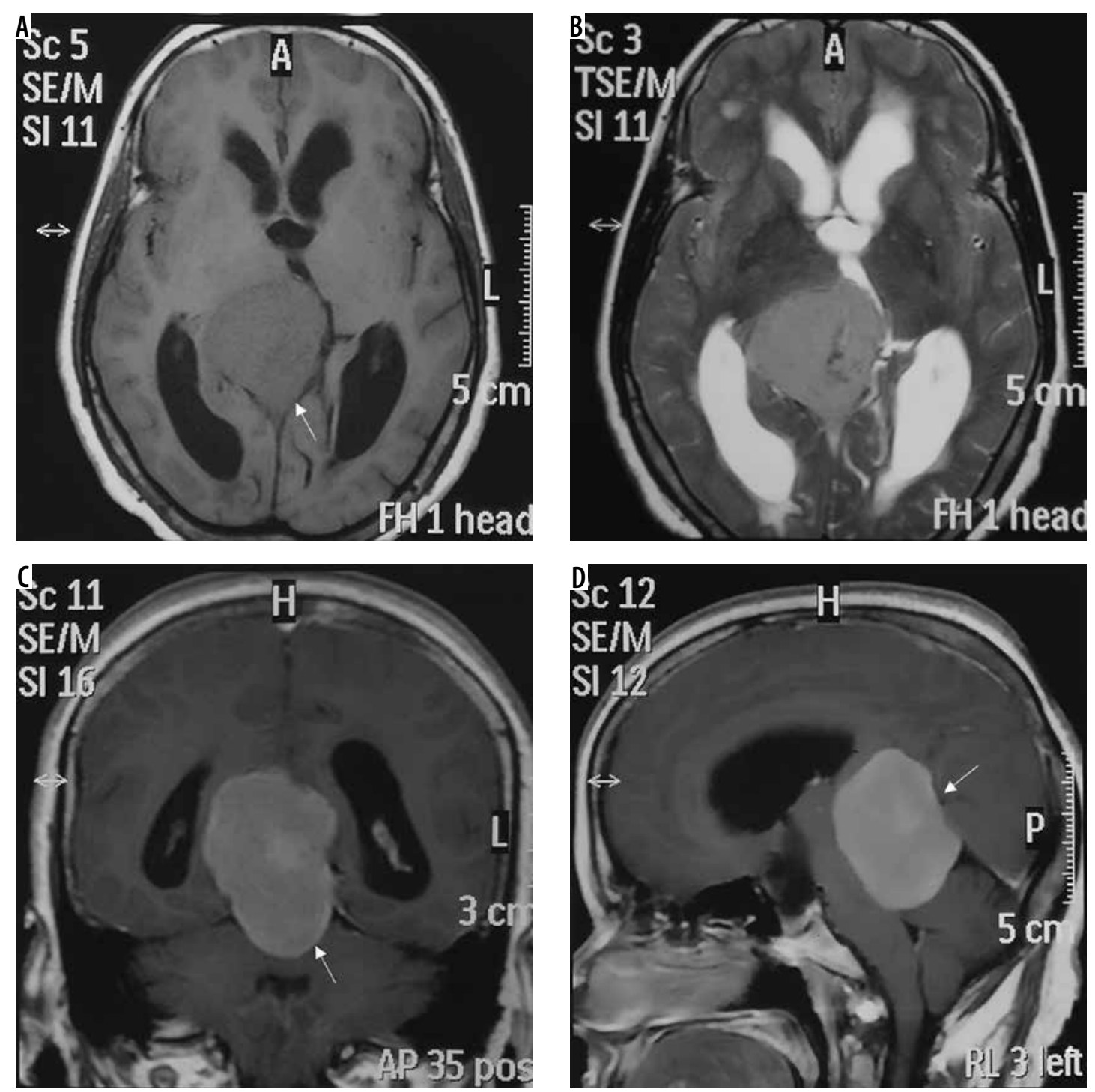

Figure 16. Tentorial apex meningioma (arrows in $A, C$, and $D$ and $B$ )

\section{Cystic changes in meningioma}

Cystic changes in meningiomas are usually associated with secretory, lymphoplasmacyte-rich, angiomatous, papillary, rhabdoid, and clear cell variants. Location-wise, they are most commonly seen in convexity meningiomas. Cystic changes in meningiomas were initially classified into four types by Nauta et al. [27]. A fifth type was later added by Worthington et al. [28], which was later histologically correlated [29]:

- type I: Intratumoural cyst centrally located within the meningioma (Figure 23);

- type II: Intratumoural cyst peripherally located within the meningioma surrounded by tumour (Figure 24);

- type III: Cyst within brain adjacent to tumour, wall formed by arachnoid (wall does not show enhancement on imaging) (Figure 25);

- type IV: Cyst between tumour and adjacent brain (entrapped CSF) (Figure 26);

- type V: Cyst wall with nest of tumour cells, wall formed by tumour cells (wall shows enhancement on imaging) (Figure 27).

Type II and Type V cystic change are usually seen in high-grade meningiomas.

\section{Conclusions}

An extensive review of the possible variations in the imaging appearance of meningiomas, including the differential features of the common and uncommon variants, would enable radiologists to not only provide accurate diagnosis but also predict their histopathological nature and WHO grade. This would be expected to improve pre-operative planning prior to surgical biopsy and thereby improve disease prognosis and patient outcomes.

\section{Disclosure}

The authors declare no conflicts of interest. 

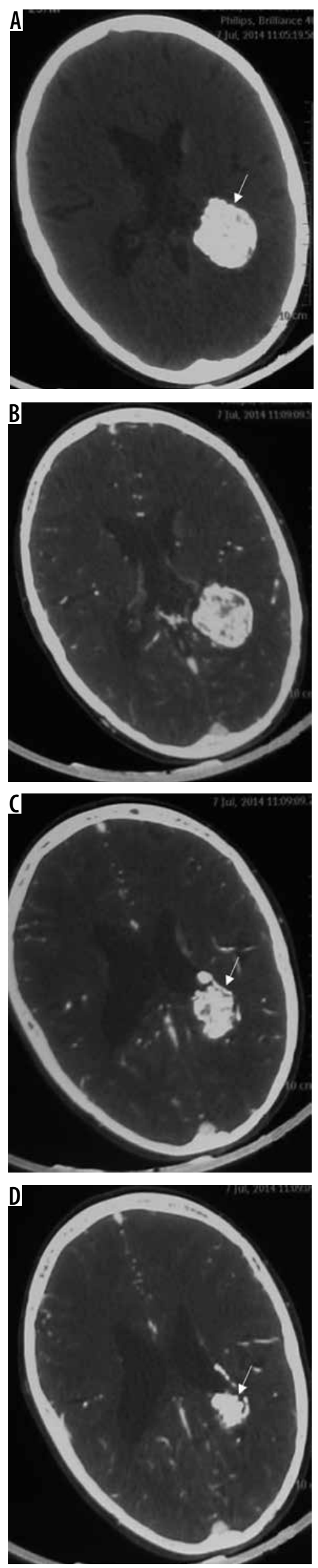

Figure 17. Intraventricular meningioma arising from left choroid plexus with dense calcification (arrows in A, C, and D and B)
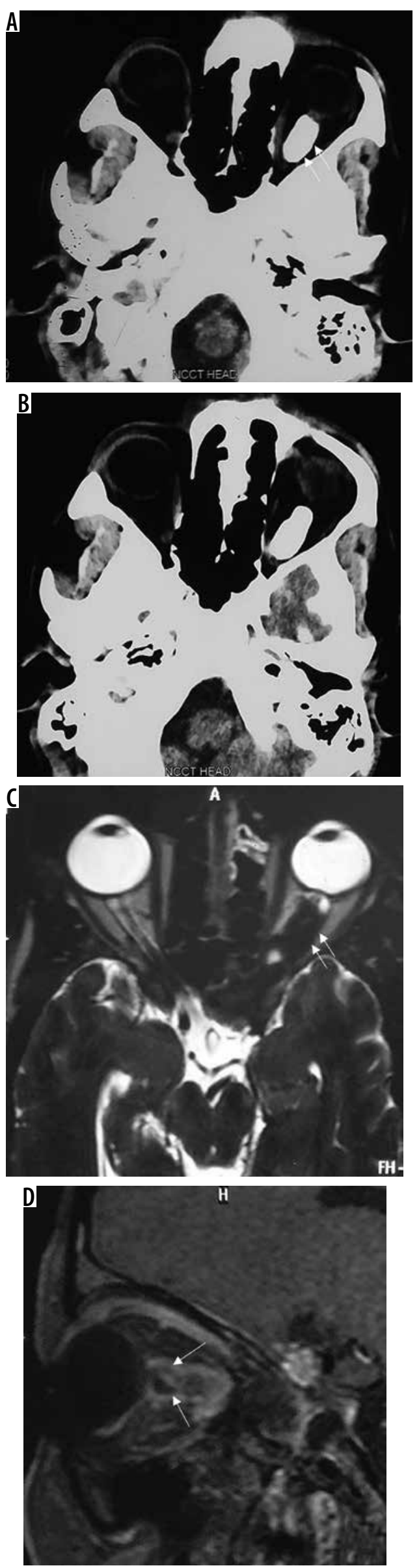

Figure 18. Optic nerve sheath meningioma showing dense calcification (arrows in A, C, and B). On T1W-CE scan the relatively hypointense optic nerve (arrows in $\mathbf{D}$ ) is seen passing through the enhancing nerve sheath meningioma ('tram track sign') 

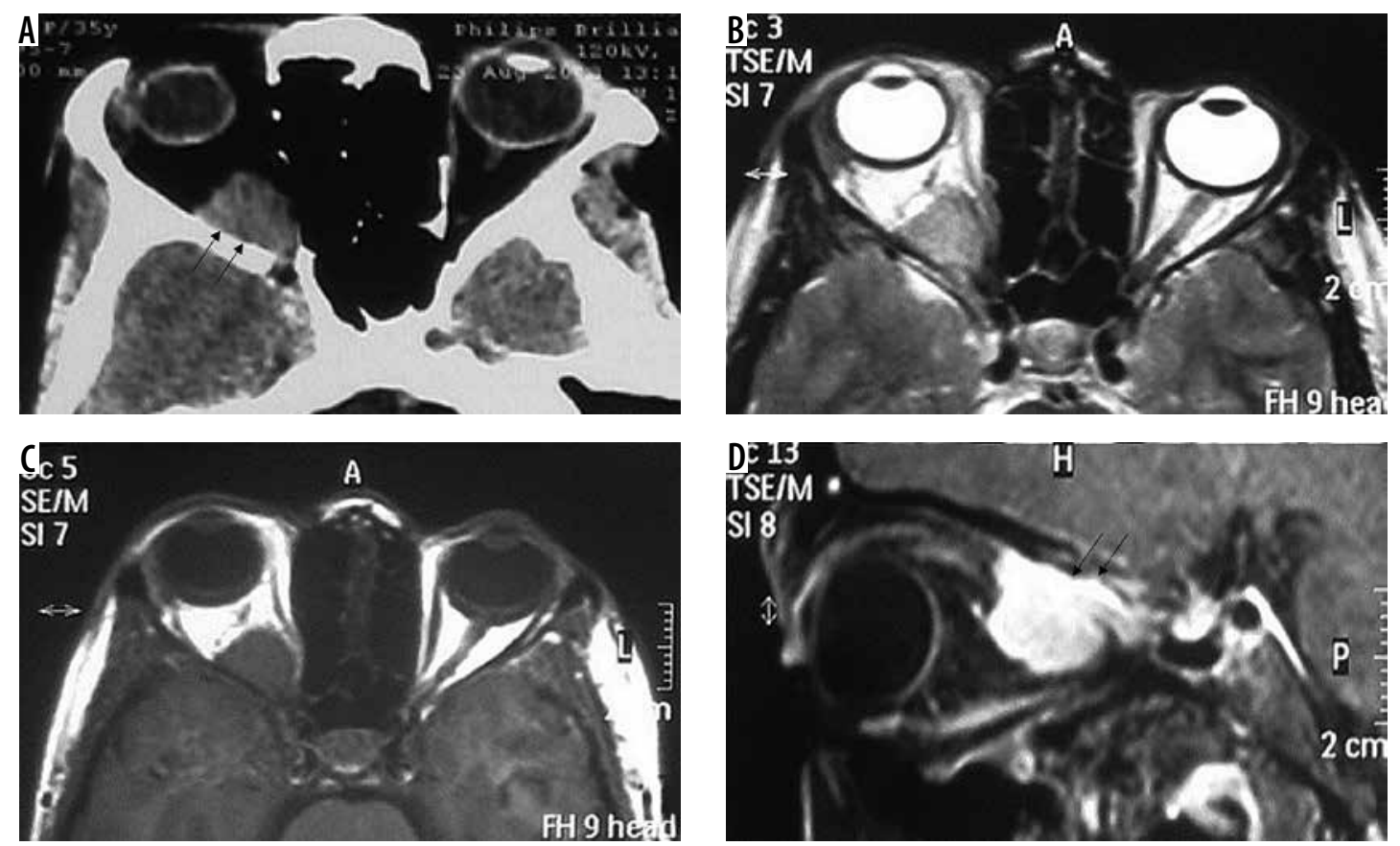

Figure 19. Orbital wall meningioma. The lesion arises from the orbital wall (arrows in A, B, and C) displacing the intra-orbital structures and shows intense enhancement on T1W-CE (D)
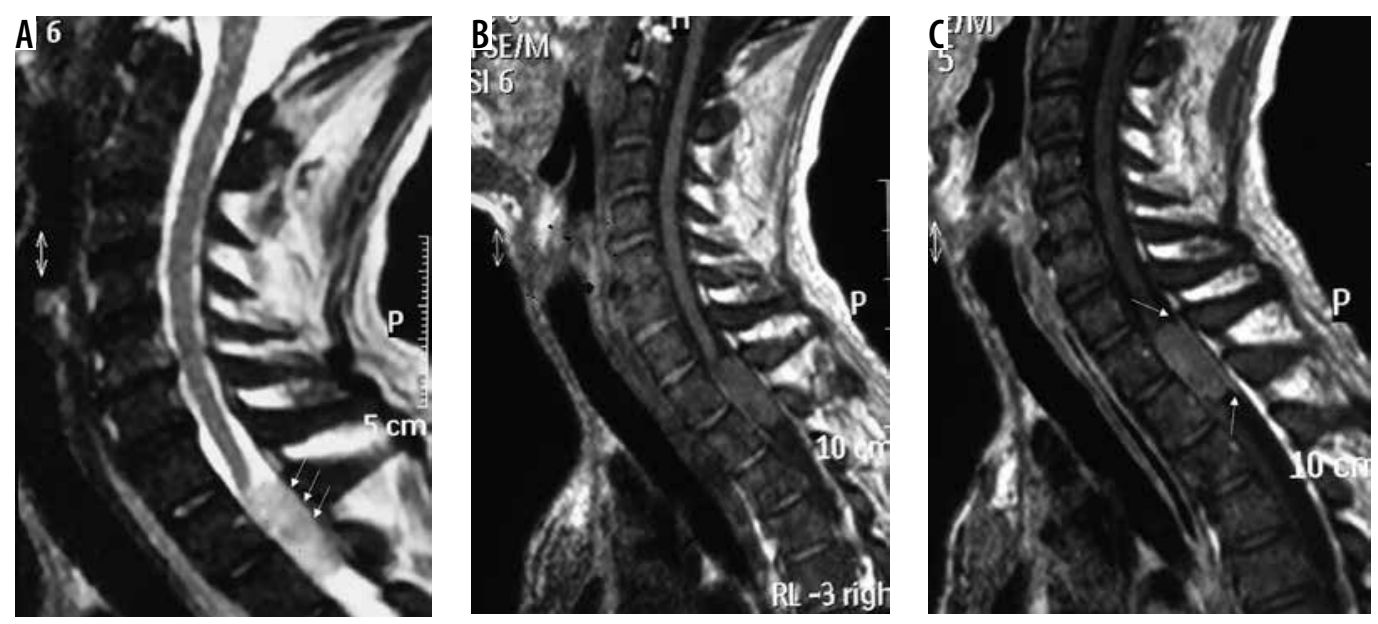

Figure 20. Upper dorsal spinal canal meningioma. The lesion is extramedullary intradural (arrows in A) and appears moderately hyperintense on T2W (A) and isointense on T1W (B) with mild enhancement on T1W-CE (C) and an obvious dural tail (arrows in C)
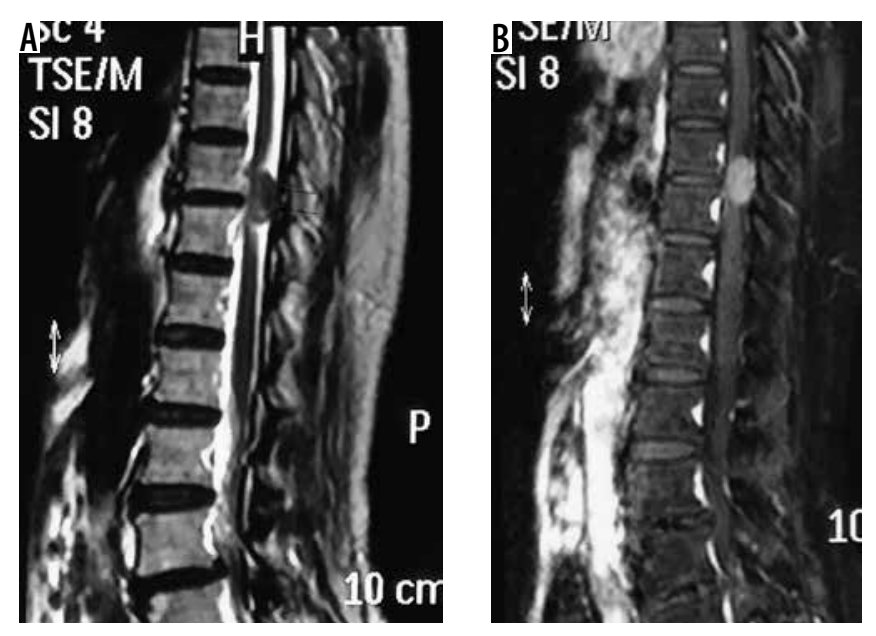

Figure 21. Lower dorsal spinal canal meningioma. The lesion is extramedullary (arrows in A) and appears mildly hypointense on T2W (A) and shows significant enhancement on T1W-CE (B) 

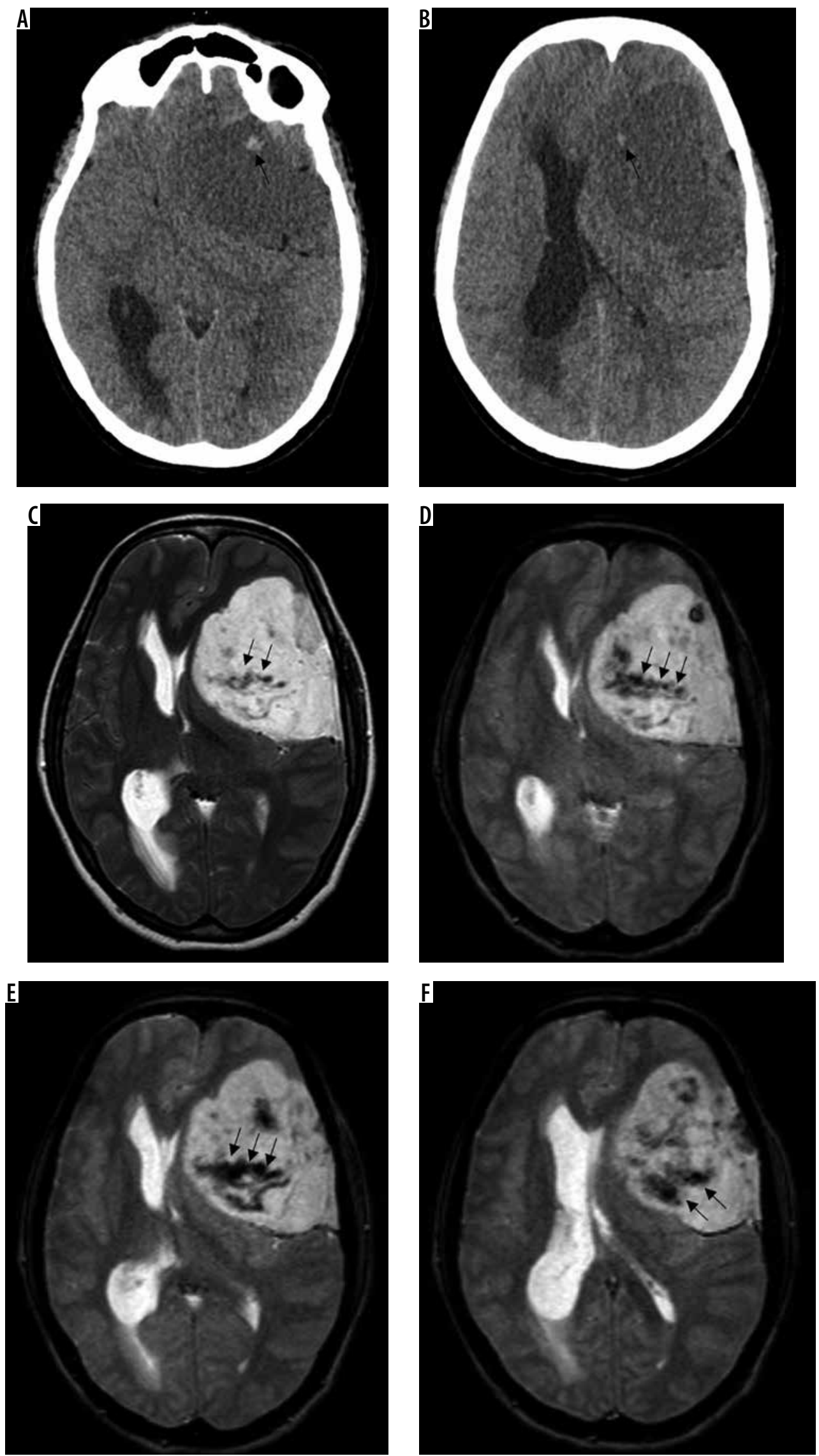

Figure 22. Same patient as in Figure 9 with xanthomatous meningioma. Few focal areas of ill-defined hyperdensity are seen within the lesion on NECT (arrows in A and B). On GRE extensive areas of blooming are seen s/0 intralesional haemorrhage within the meningioma (arrows in C, D, E, and F) 

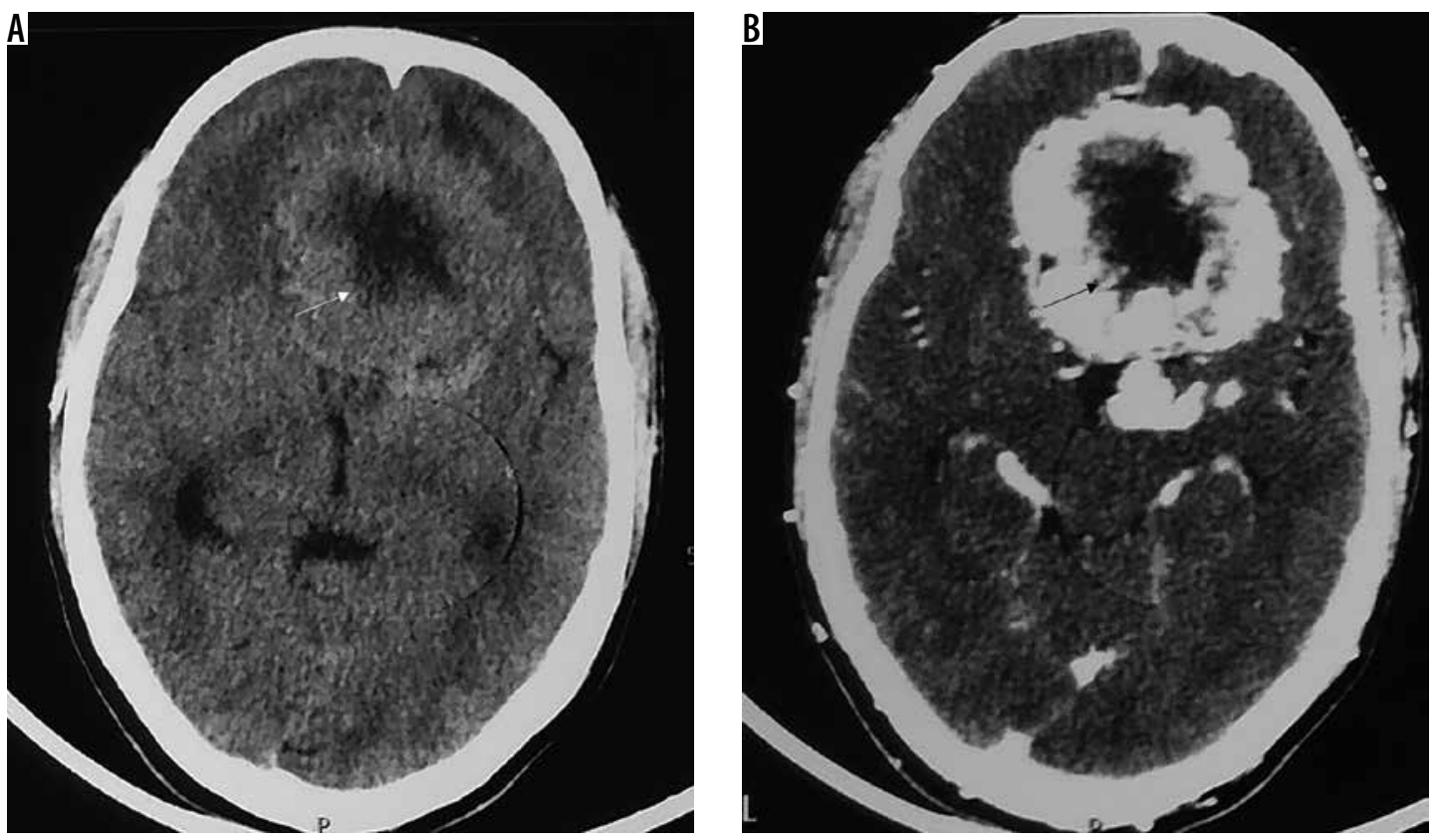

Figure 23. Type I cystic meningioma. Same patient as in Figure 5 with angiomatous meningioma. Intratumoural cystic change in centre of the meningioma (arrows in A and B)
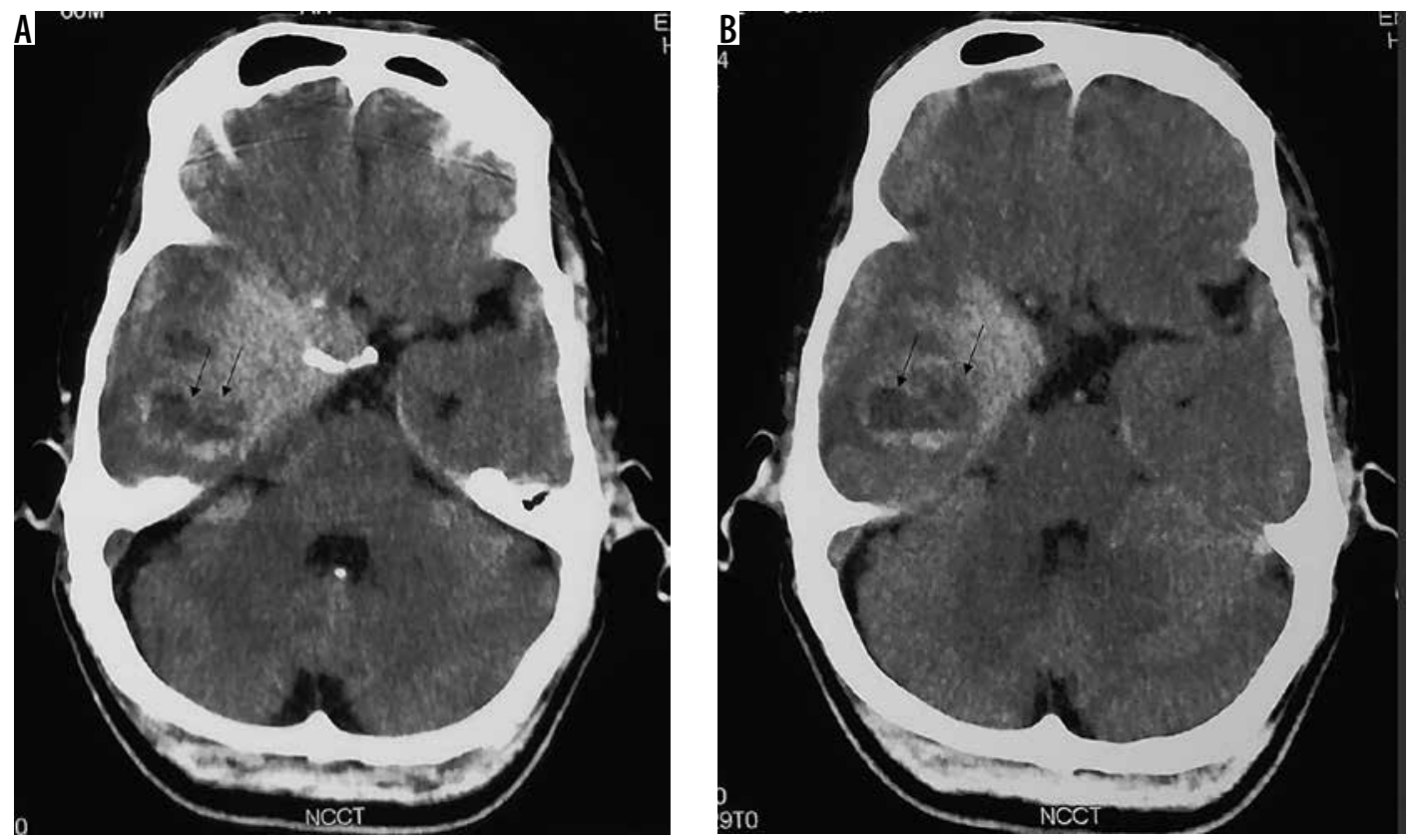

Figure 24. Type II cystic meningioma. Same patient as in Figure 12 with atypical/high-grade meningioma. Intratumoural cystic change in peripheral part of meningioma (arrows in A and B) 

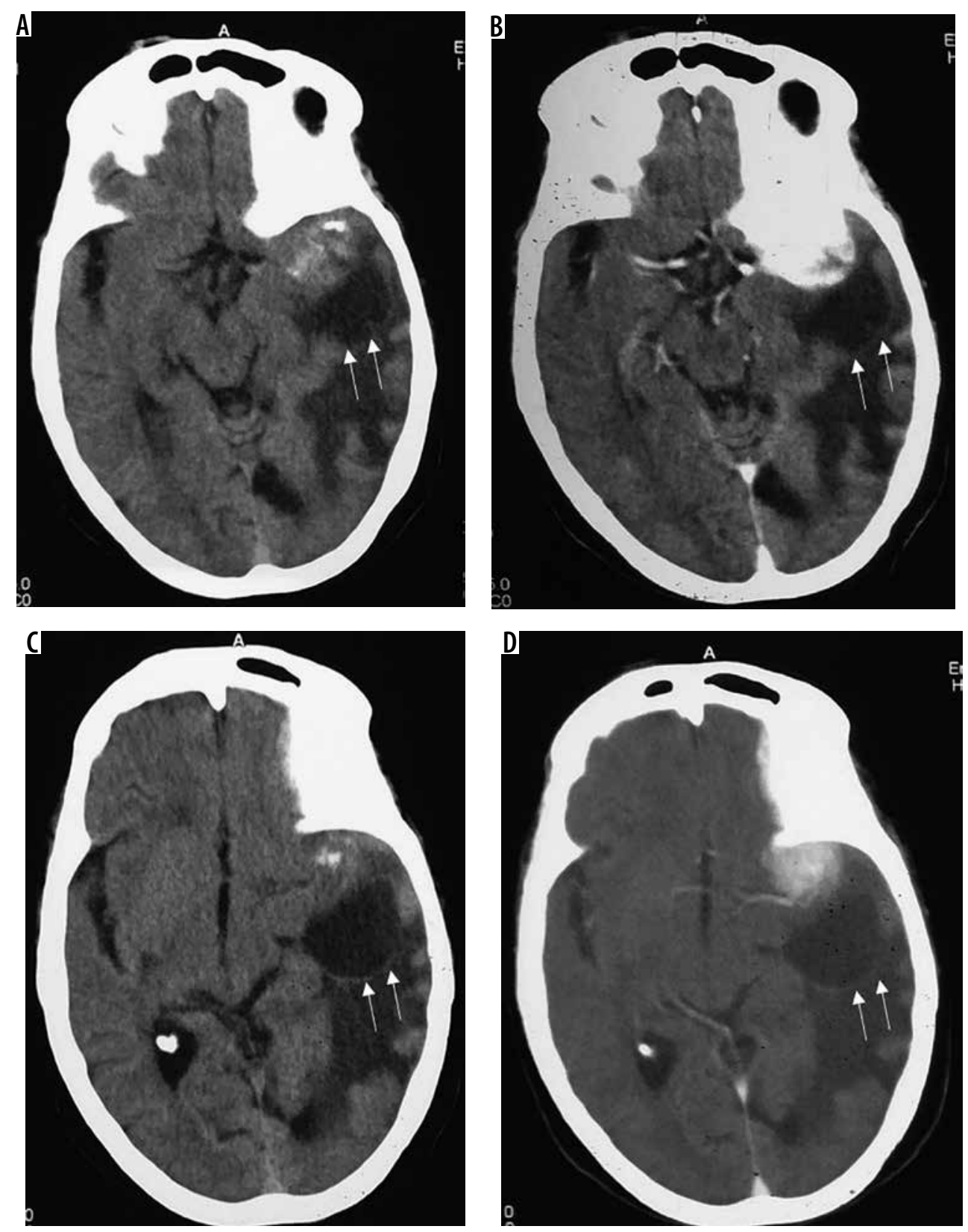

Figure 25. Type III cystic meningioma. Peritumoral cyst in adjacent brain parenchyma without cyst wall enhancement (arrows in A, B, C, and D)
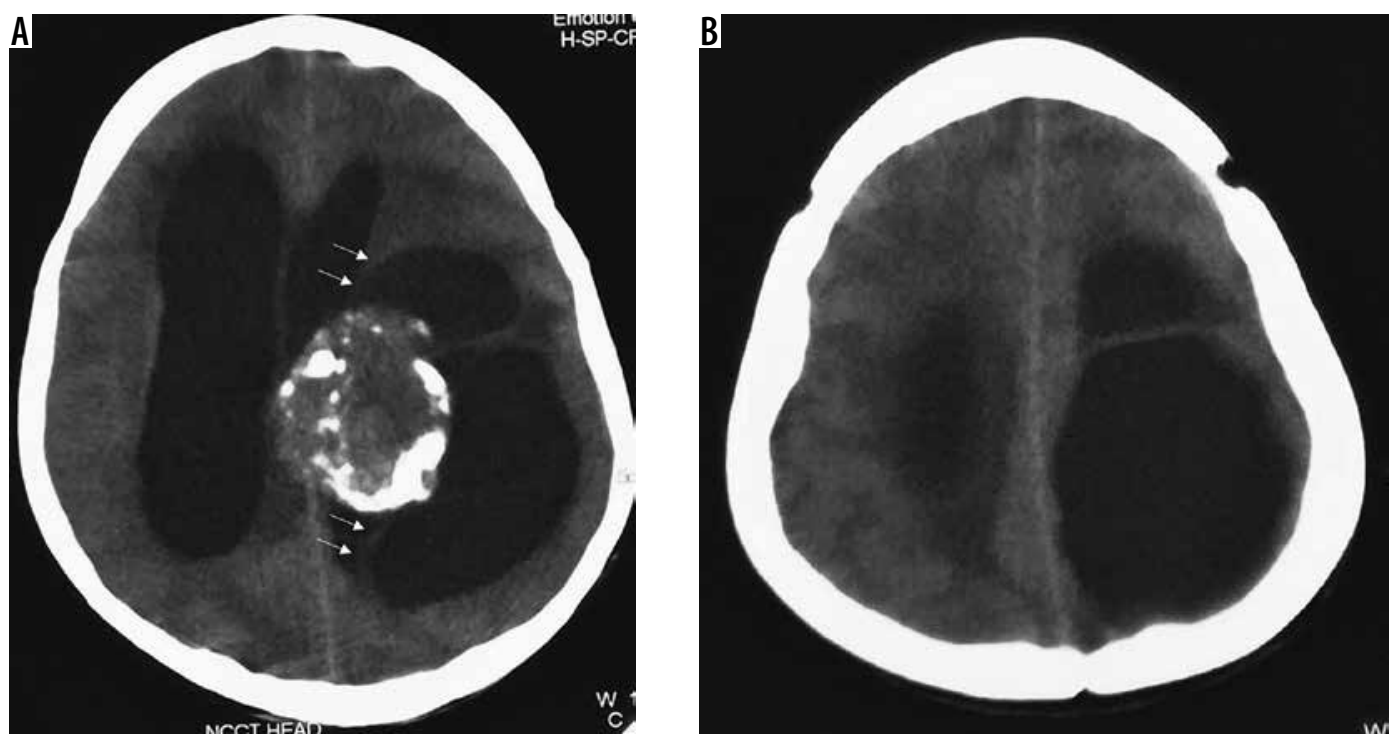

Figure 26. Type IV cystic meningioma. Peritumoral cyst between meningioma and adjacent brain parenchyma without cyst wall enhancement (arrows in A and B) 

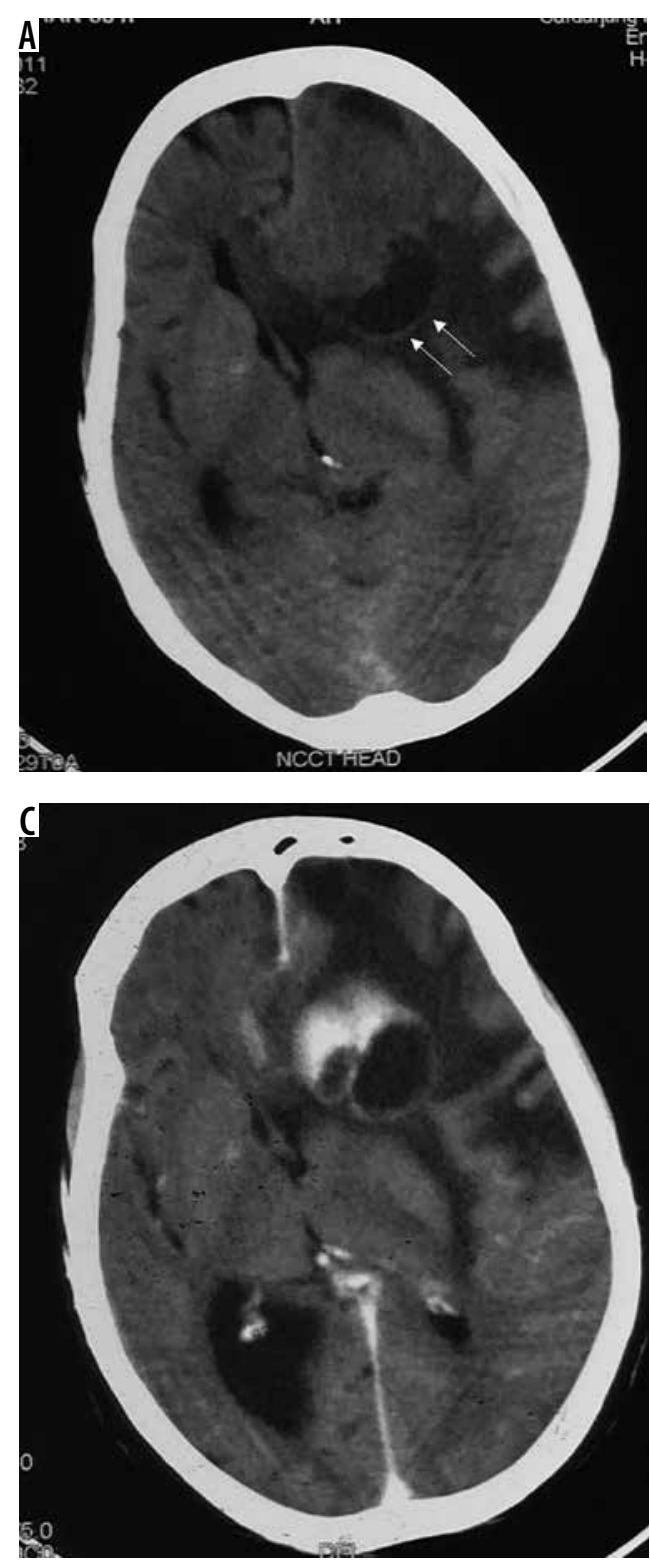

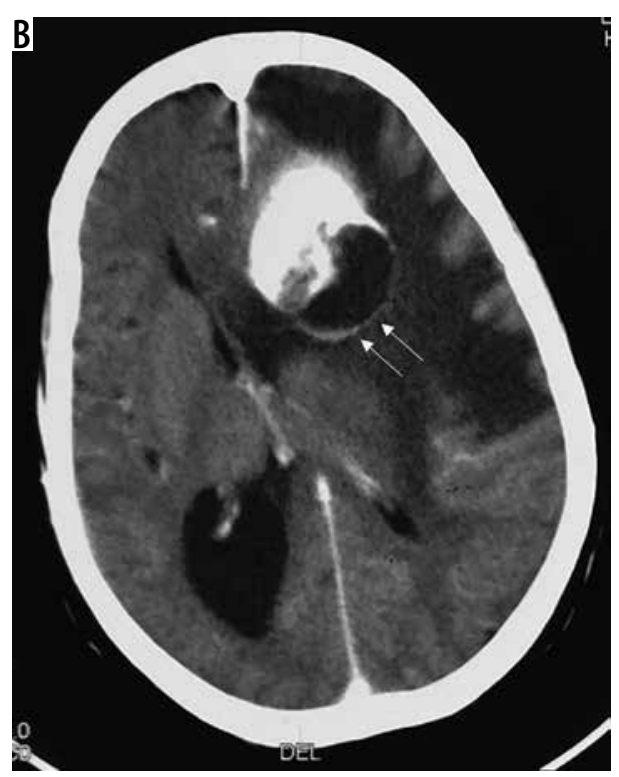

Figure 27. Type $V$ cystic meningioma. Tumoral cyst with nest of tumour cells and with perceptible cyst wall enhancement (arrows in A, B, and C)

References

1. Bondy M, Ligon BL. Epidemiology and etiology of intracranial meningiomas: a review. J Neurooncol 1996; 29: 197-205.

2. Baldi I, Engelhardt J, Bonnet C, et al. Epidemiology of meningiomas. Neurochirurgie 2018; 64: 5-14.

3. Porter KR, McCarthy BJ, Freels S, et al. Prevalence estimates for primary brain tumors in the United States by age, gender, behavior, and histology. Neuro Oncol 2010; 12: 520-527.

4. McCarthy BJ, Davis FG, Freels S, et al. Factors associated with survival in patients with meningioma. J Neurosurg 1998; 88: 831-839.

5. Simon M, Bostrom JP, Hartmann C. Molecular genetics of meningiomas: from basic research to potential clinical applications. Neurosurgery 2007; 60: 787-798.

6. Umansky F, Shoshan Y, Rosenthal G, et al. Radiation-induced meningioma. Neurosurg Focus 2008; 24: E7.

7. Yamamoto J, Takahashi M, Idei M, et al. Clinical features and surgical management of intracranial meningiomas in the elderly. Oncol Lett 2017; 14: 909-917.
8. Harter PN, Braun Y, Plate KH. Classification of meningiomas advances and controversies. Chin Clin Oncol 2017; 6 (Suppl 1): S2.

9. Ko KW, Nam DH, Kong DS, et al. Relationship between malignant subtypes of meningioma and clinical outcome. J Clin Neurosci J Neurosurg Soc Australas 2007; 14: 747-753.

10. Bhat AR, Wani MA, Kirmani AR, Ramzan AU. Histological subtypes and anatomical location correlated in meningeal brain tumors (meningiomas). J Neurosci Rural Pract 2014; 5: 244-249.

11. Buetow MP, Buetow PC, Smirniotopoulos JG. Typical, atypical, and misleading features in meningioma. Radiographics 1991; 11: 10871106.

12. Yue Q, Isobe T, Shibata $Y$, et al. New observations concerning the interpretation of magnetic resonance spectroscopy of meningioma. Eur Radiol 2008; 18: 2901-2911.

13. Lee JW, Lee IS, Choi KU, et al. CT and MRI findings of calcified spinal meningiomas: correlation with pathological findings. Skelet Radiol 2010; 39: 345-352. 
14. Liu Z, Wang C, Wang $\mathrm{H}$, et al. Clinical characteristics and treatment of angiomatous meningiomas: a report of 27 cases. Int J Clin Exp Pathol 2013; 6: 695-702.

15. Chen CJ, Tseng YC, Hsu HL, Jung SM. Microcystic meningioma: importance of obvious hypointensity on T1-weighted magnetic resonance images. J Comput Assist Tomogr 2008; 32: 130-134.

16. Wang DJ, Xie Q, Gong Y, et al. Secretory meningiomas: clinical, radiological and pathological findings in 70 consecutive cases at one institution. Int J Clin Exp Pathol 2013; 6: 358-374.

17. Yongjun L, Xin L, Qiu S, Jun-Lin Z. Imaging findings and clinical features of intracal lymphoplasmacyte-rich meningioma. J Craniofac Surg 2015; 26: 132-137.

18. Ishida M, Fukami T, Nitta N, et al. Xanthomatous meningioma: a case report with review of the literature. Int J Clin Exp Pathol 2014; 6: 2242-2246.

19. Pond JB, Morgan TG, Hatanpaa KJ, et al. Chordoid meningioma: Differentiating a rare World Health Organization grade II tumor from other meningioma histologic subtypes using MRI. AJNR Am J Neuroradiol 2015; 36: 1253-1258.

20. Wang XQ, Huang MZ, Zhang $H$, et al. Clear cell meningioma: clinical features, CT, and MR imaging findings in 23 patients. J Comput Assist Tomogr 2014; 38: 200-208.

21. Lalwani AK, Jackler RK. Preoperative differentiation between meningioma of the cerebellopontine angle and acoustic neuroma using MRI. Otolaryngol Head Neck Surg 1993; 109: 88-95.
22. Kawahara Y, Nakada M, Hayashi Y, et al. Prediction of high-grade meningioma by preoperative MRI assessment. J Neurooncol 2012; 108: 147-152.

23. Hakyemez B, Yildirim N, Gokalp G, et al. The contribution of diffusion-weighted MR imaging to distinguishing typical from atypical meningiomas. Neuroradiology 2006; 48: 513-520.

24. Bitzer M, Opitz H, Popp J, et al. Angiogenesis and brain oedema in intracranial meningiomas: influence of vascular endothelial growth factor. Acta Neurochir (Wien) 1998; 140: 333-340.

25. Nakano T, Asano K, Miura H, et al. Meningiomas with brain edema: radiological characteristics on MRI and review of the literature. Clin Imaging 2002; 26: 243-249.

26. Bosnjak R, Derham C, Popović M, Ravnik J. Spontaneous intracranial meningioma bleeding: clinicopathological features and outcome. J Neurosurg 2005; 103: 473-484.

27. Nauta HJW, Tucker WS, Horsey WJ, et al. Xanthochromic cysts associated with meningioma. J Neurol Neurosurg Psychiatry 1979; 42: 529-535.

28. Worthington C, Caron JL, Melanson D, Leblanc R. Meningioma cysts. Neurology 1985; 35: 1720-1724.

29. Go KO, Lee K, Heo W, et al. Cystic meningiomas: correlation between radiologic and histopathologic features. Brain Tumor Res Treat 2018; 6: 13-21. 